\title{
Unsteady Flow Interactions Between the LH2 Feed Line and SSME LPFP Inducer
}

\author{
Daniel Dorney ${ }^{*}$ and Lisa Griffin. ${ }^{\dagger}$ \\ NASA George C. Marshall Space Flight Center, MSFC, AL, 35812 \\ Bogdan Marcu ${ }^{\ddagger}$ and Morgan Williams ${ }^{\S}$ \\ Pratt \& Whitney - Rocketdyne, Canoga Park, CA, 91309
}

\begin{abstract}
An extensive computational effort has been performed in order to investigate the nature of unsteady flow in the fuel line supplying the three Space Shuttle Main Engines during flight. Evidence of high cycle fatigue (HCF) in the flow liner one diameter upstream of the Low Pressure Fuel Pump inducer has been observed in several locations. The analysis presented in this report has the objective of determining the driving mechanisms inducing HCF and the associated fluid flow phenomena. The simulations have been performed using two different computational codes, the NASA MSFC PHANTOM code and the Pratt and Whitney Rocketdyne ENIGMA code. The fuel flow through the flow liner and the pump inducer have been modeled in full three-dimensional geometry, and the results of the computations compared with test data taken during hot fire tests at NASA Stennis Space Center, and cold-flow water flow test data obtained at NASA MSFC. The numerical results indicate that unsteady pressure fluctuations at specific frequencies develop in the duct at the flow-liner location. Detailed frequency analysis of the flow disturbances is presented. The unsteadiness is believed to be an important source for fluctuating pressures generating high cycle fatigue.
\end{abstract}

$\begin{array}{ll}N & =\text { rotational speed } \\ N S S & =\text { suction specific speed } \\ P i & =\text { inlet static pressure } \\ Q & =\text { volumetric flow rate } \\ R P L & =\text { rated power level } \\ R P M & =\text { revolutions per minute }\end{array}$

\section{Nomenclature}

I. Introduction

$\mathrm{D}$

uring a routine post-flight inspection of the liquid hydrogen (LH2) feed lines in the Shuttle Main Propulsion System (SMPS) leading to the Space Shuttle Main Engines (SSME), cracks were discovered between adjacent slots in a flow liner just upstream of the low pressure fuel pump (LPFP) inducer (see Fig. 1). The flow liner is located at a gimbal joint less than one duct diameter upstream of the LPFP inducer and has two rows of 38 slots each (see Fig. 2). The slots are stamped into the liner to allow for cleaning of the bellows located in the cavity behind the liner. The majority of the cracks were found in the downstream slots (closest to the inducer). Upon further examination it has been found that the cracks propagated in both the flow and slot-to-slot directions.

An extensive series of hot-fire tests, water-flow tests, air-flow tests and numerical simulations were performed to determine the cause of the cracks, as well as to determine the risks they posed. The purpose of this paper is to present results from some of the numerical simulations performed for the feed line and LPFP inducer. The numerical

\footnotetext{
* Aerospace Engineer, Propellant Delivery Fluids Branch, ER42, Associate Fellow AIAA.

${ }^{\dagger}$ Branch Chief, Propellant Delivery Fluids Branch, ER42, Senior Member AIAA.

${ }^{\ddagger}$ Engineering Scientist, Senior Member, AIAA.

${ }^{8}$ Associate Technical Fellow, Advanced Analysis Department, Computational Fluid Dynamics Group, MC iB39.
} 
simulations were conducted using the two different analyses, the PHANTOM code of NASA Marshall Space Flight Center [1] and the ENIGMA code of Pratt \& Whitney Rocketdyne [2]. The numerical simulations were performed for $\mathrm{LH} 2$, water $(\mathrm{H} 2 \mathrm{O})$ and air. Both engine (hot fire) and scaled (water, air flow) operating conditions were considered. The effects of eccentric tip clearance and duct angulation were also studied. The general goal of the simulations was to characterize the unsteadiness upstream of the SSME LPFP inducer, while the specific goals were to isolate the sources of unsteadiness reaching the flow liner and provide guidance for the tests. The predicted results were compared with analytical solutions, hot-fire data and water flow data.



Figure 1. Slot-to-slot and flow stream direction cracks in the flow liner.

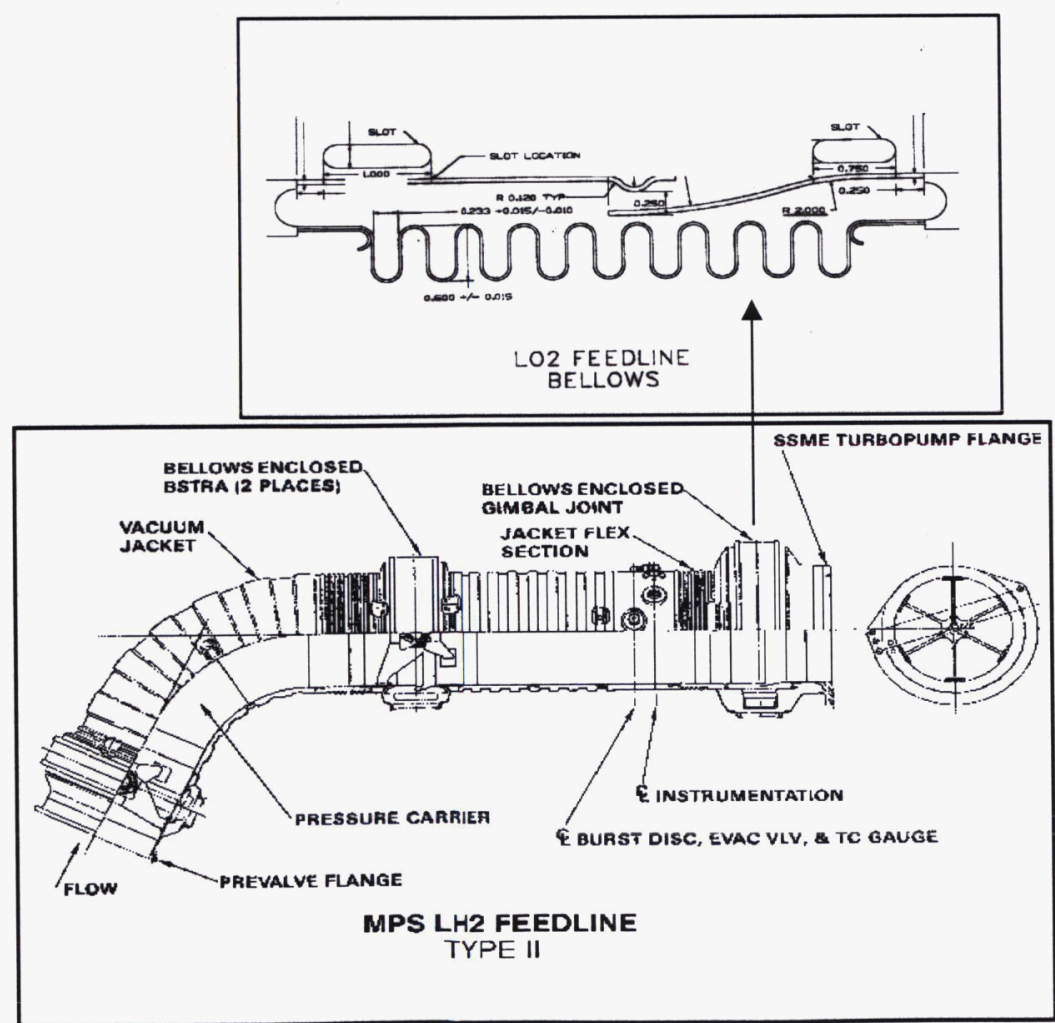

Figure 2. Flow liner at gimbal joint, just upstream of the LPFP inducer. 


\section{Numerical Procedures}

The governing equations in the PHANTOM code are the three-dimensional, unsteady, Navier-Stokes equations. The equations have been written in the Generalized Equation Set (GES) format, enabling it to be used for both liquids and gases at operating conditions ranging from incompressible to supersonic flow. The code employs a system of overset $\mathrm{O}$-grids and $\mathrm{H}$-grids to discretize the flow field. The grids move to simulate blade motion. A modified Baldwin-Lomax turbulence model is used for turbulence closure [3]. The code contains two options for the fluid properties. The first option is based on the equations of state, thermodynamic departure functions and corresponding state principles constructed by Oefelein [4]. The second option is based on splines generated from the NIST Tables [5]. Message Passing Interface (MPI) protocols are used for parallel simulations. The code can model two-phase flows (e.g., cavitation) using the GES extensions of Merkle et. al. [6] and Ahuja et al. [7]. A detailed description of the code/algorithm development, as well as its application to several turbine and pump test cases, is presented in Refs. 1 and 8.

The Enigma CFD code is a structured-grid finite-difference code capable of solving incompressible and subsonic compressible, steady (e.g., frozen-rotor) and unsteady (e.g., rotor-stator) flow problems and it features a parallel solution algorithm implemented in terms of the MPI parallel programming library. The numerical method uses the standard $k-\varepsilon$ turbulence model with wall functions and also features a length-scale filtered $k-\varepsilon$, turbulence model suitable for capturing resident flow unsteadiness. More details of the code and its development can be found in Refs. 2,9 and 10 .

\section{Numerical Simulations}

The SSME LPFP inducer operates in LH2 and has four main blades and four splitter blades. At the nominal (104.5\% RPL) operating conditions the inducer rotates at 15,761 RPM and has a mass flow of approximately 155 $\mathrm{lbm} / \mathrm{sec}$. Simulations were performed for operating conditions from $65 \%$ RPL to $104.5 \%$ RPL.

\section{A. Phantom Simulations}

Several sets of simulations were performed with the PHANTOM code. The simulations were performed at engine scale conditions for $\mathrm{LH} 2, \mathrm{H} 2 \mathrm{O}$ and air over the range of flow conditions between $65 \%$ and $104.5 \% \mathrm{RPL}$. A series of CFD simulations for $\mathrm{H} 2 \mathrm{O}$ were also performed at $51 \%$ scale, corresponding to the actual hardware used in the water flow tests [11]. The full-annulus computational grid for the inducer (including 22 inches of the feed line) contained approximately 2.8 million grid points for cases without cavitation modeled, and 4.6 million grid points for cases including cavitation. The grids for the non-cavitating simulations are shown in Fig. 3. It was decided that only the main blades would be used in the simulations because the splitter blades are located towards the downstream end of the inducer passage, and would have little effect on the unsteadiness at the flow liner. In addition, the inducer blades were allowed to scrape along the shroud (i.e., the tip clearance was set to 0 ) in the non-cavitating simulations. In the simulations with cavitation the nominal value for the tip clearance was used. Note that the assumptions made on the splitter blades and tip clearance (in the non-cavitating cases) will have an impact on the performance of the inducer. The simulations were performed on 12 processors of the SGI Altix clusters located at NASA Ames Research Center and NASA Marshall Space Flight Center. Approximately 6 revolutions of the inducer equate to one through-flow cycle (i.e., the time required by a fluid particle to move from the computational inlet to the computational exit), so all the non-cavitating simulations were run for at least 12 revolutions. The cavitating simulations were initiated from the non-cavitating solutions and run for an additional 5 revolutions. 


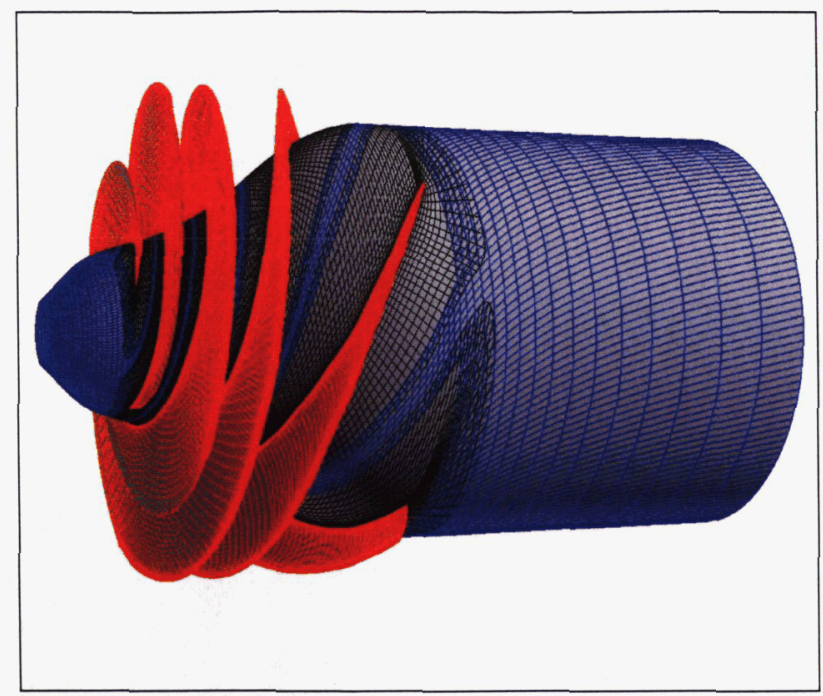

Figure 3. Computational grid for the non-cavitating PHANTOM simulations.

Two views of the time-averaged static pressure contours from the $104.5 \%$ RPL simulation in LH2 are shown in Figs. 4 and 5. The contours highlight the low pressure region near the tip leading edge where the inception of cavitation is normally observed. The predicted time-averaged static and total head rise coefficients are compared with results of half-scale water flow tests in Fig. 6 over a range of operating conditions [11]. In general, fair agreement is noted between the predicted and experimental performance curves. The differences are attributed to several factors, including: a) the baseline simulations were assumed to be non-cavitating, and b) the baseline simulations were performed without the inclusion of tip clearance

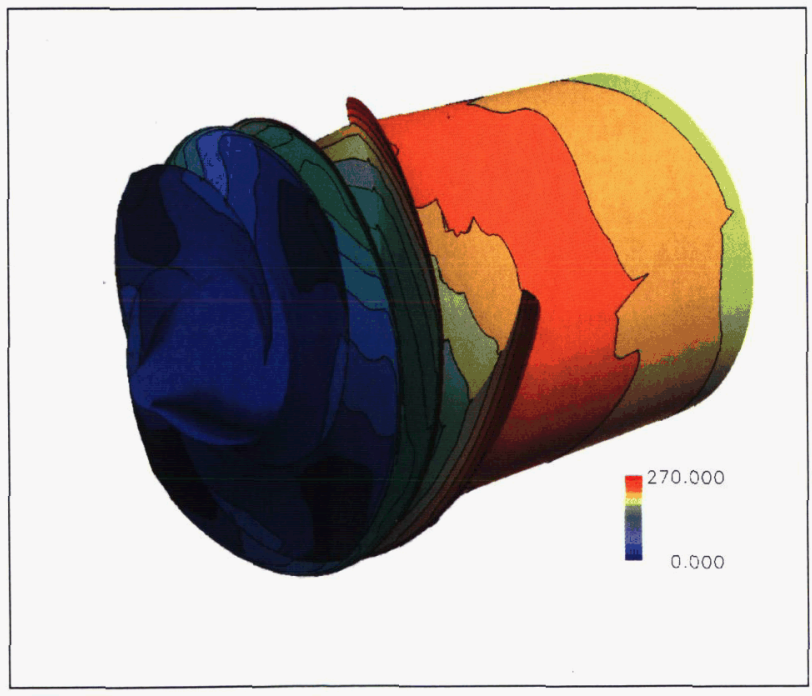

Figure 4. Static pressure (psi) on the SSME LPFP inducer - LH2 - view 1. 


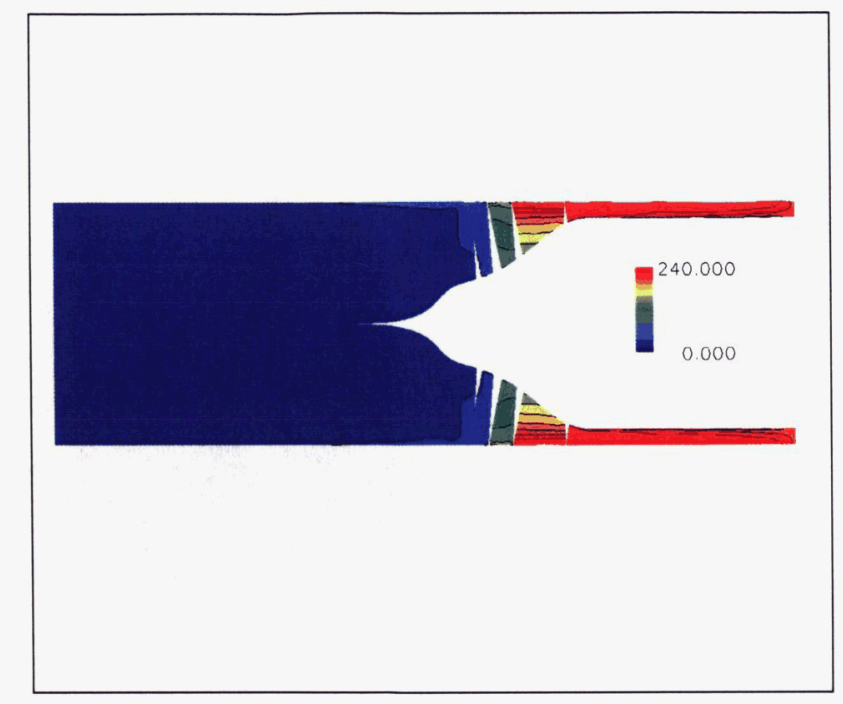

Figure 5. Static pressure (psi) on the SSME LPFP inducer - LH2 - view 2.

The large difference in static pressure between the suction and pressure surfaces (i.e., loading) at the inducer tip leading edge creates a movement of flow upstream from this region. This "backflow" from the inducer is composed of two distinct phenomena. The first is a convective component, which behaves much like the wake from an airfoil. It is characterized by swirling flow whose axial flow component moves upstream towards the inlet. The second component is a potential or pressure wave. The pressure wave component, in some cases, can persist much longer than the convective component. Figure 7 shows contours of the axial velocity ( $\mathrm{ft} / \mathrm{sec}$ ), which highlights the backflow, for $104.5 \%$ RPL conditions. Figure 8 displays the trends in the backflow for LH2 and H2O over a range of operating conditions. The convective component of the backflow from inducer reaches the flow liner $(7$ inches upstream of the inducer) even at $104.5 \%$ RPL, and encompasses the flow liner near $80 \%$ RPL.

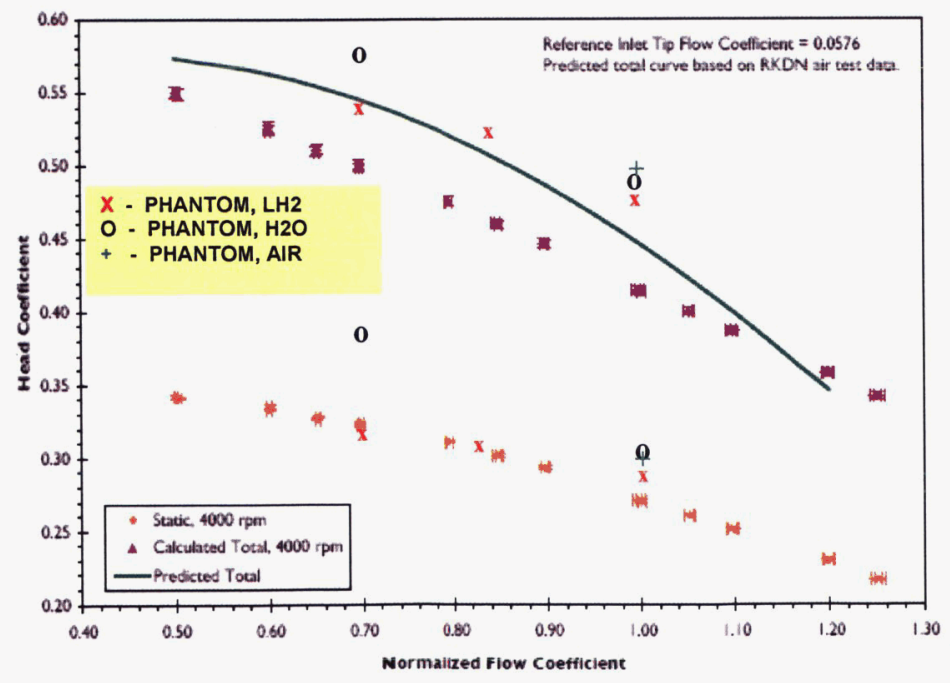

Figure 6. Predicted and experimental head rise coefficients for the LPFP inducer. 


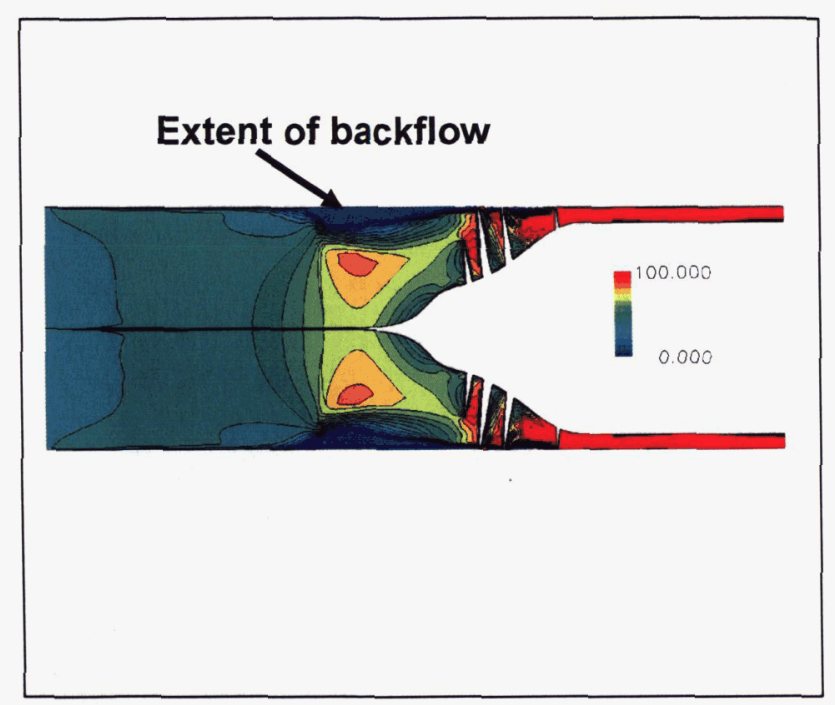

Figure 7. Contours of axial velocity highlighting backflow from the LPFP inducer

The predicted attenuation of the unsteady pressure waves upstream of the inducer at $65 \%$ and $104.5 \%$ RPL, along with the results of an analytical wave model [12] and hot-fire data [13] are shown in Figs. 9 and 10. Also shown in Figs. 9 and 10 is a decomposition of the unsteady pressure at various locations upstream of the inducer leading edge $(\mathrm{X}=0 \mathrm{in})$ for $104.5 \% \mathrm{RPL}$. The unsteady pressure amplitude at the inducer leading edge predicted in the CFD was used as input to the wave model. All four data sets show an exponential decrease in the pressure with distance upstream of the inducer leading edge. The rate of decay is somewhat greater in the CFD prediction than the data indicates.

The amplitude of the unsteady pressure is low, but not insignificant, by the time it reaches the flow liner. The predominant unsteadiness occurs at the inducer blade passing frequency (approximately $1000 \mathrm{~Hz}$ ) or its first harmonic. Many structural frequencies lie in the neighborhood of $1000 \mathrm{~Hz}$ and may contribute to the cracking process. The energy content predicted by the CFD simulations matches the energy content measured in the tests, however, the test data spectrum displays a significant amount of additional frequencies in terms of higher harmonics and noise. The additional frequencies identified in the experiments are due to the presence of phenomena such as cavitation, which were not modeled in the simulations shown in Figs. 9 and 10.

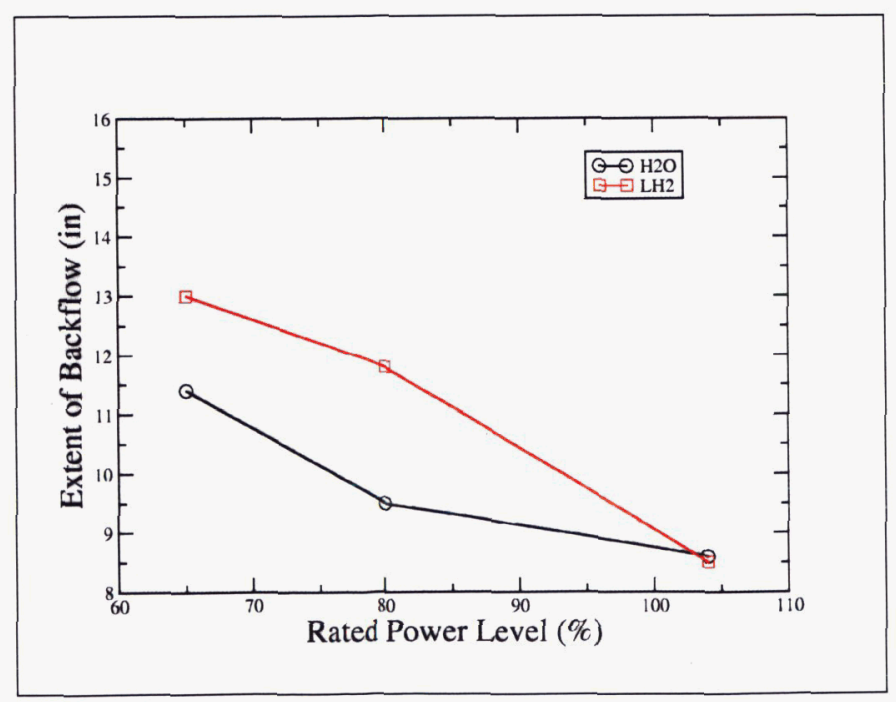

Figure 8. Variation of backflow with power level. 




Figure 9. Decay of the unsteady pressure upstream of inducer $(X=0$ in is the inducer leading edge $)$ LH2

CFD simulations of water flow LPFP and duct operation have been made for full-scale hardware and half-scale hardware, the latter case corresponding to the actual water flow test hardware. In each case, a flow scaling has been made in order to obtain the flow regime equivalent to $104.5 \%$ and $65 \%$ RPL. In the case of full scale hardware, an arbitrary rotational speed was chosen, and the flow coefficient value matched. The predicted unsteady pressure data for the full scale water simulations at $104.5 \%$ RPL is compared to half-scale water rig data in Figs. 11 to 13 [13]. The CFD predicted decay rates show good agreement with the measurements.

The CFD simulations performed for water at the exact scale of the hardware used in testing allows for a more consistent comparison between prediction and measurement. In the water flow experiments, the flow regime corresponding to the $104.5 \%$ RPL of the SSME has been considered, i.e., the $100 \% \mathrm{Q} / \mathrm{N}$ regime [11]. Consequently, the $65 \%$ RPL of the SSME corresponds to $50 \% \mathrm{Q} / \mathrm{N}$ regime in water flow testing. Figure 12 presents a direct comparison between CFD and test in terms of pressure fluctuations upstream of the inducer for $100 \% \mathrm{Q} / \mathrm{N}$, while Fig. 13 shows the comparison for $50 \%$ Q/N. For $100 \%$ Q/N, the main frequencies identified in both the simulation and the experiment include: the blade passing $(4 \mathrm{~N})$ and 2 upper harmonics $(8 \mathrm{~N}$ and $16 \mathrm{~N})$. The predicted amplitudes show extremely close agreement to the experiment. The pressure wave attenuation is achieved at half a diameter upstream, similar to the Fig. 11. For $50 \% \mathrm{Q} / \mathrm{N}$ the CFD prediction displays the $4 \mathrm{~N}$ and 2 upper harmonics, while the measurement indicates a full train of upper harmonics frequencies. As mentioned above, cavitation processes are a possible cause for the richer spectrum, and stronger amplitudes in the experiment. The decay rates for the pressure fluctuation upstream is nevertheless well predicted: it is remarkable that in spite of more than double the amplitude at inducer leading edge, the pressure wave depth of penetration upstream is not larger for the $50 \% \mathrm{Q} / \mathrm{N}$ case. Both measurement and CFD prediction show this clearly. For both regimes, a low frequency corresponding to $1 \mathrm{~N}$ propagates upstream with less attenuation. Both the numerical and experimental data indicate about $0.5 \mathrm{psi}$ amplitude for the $1 \mathrm{~N}$ wave. 


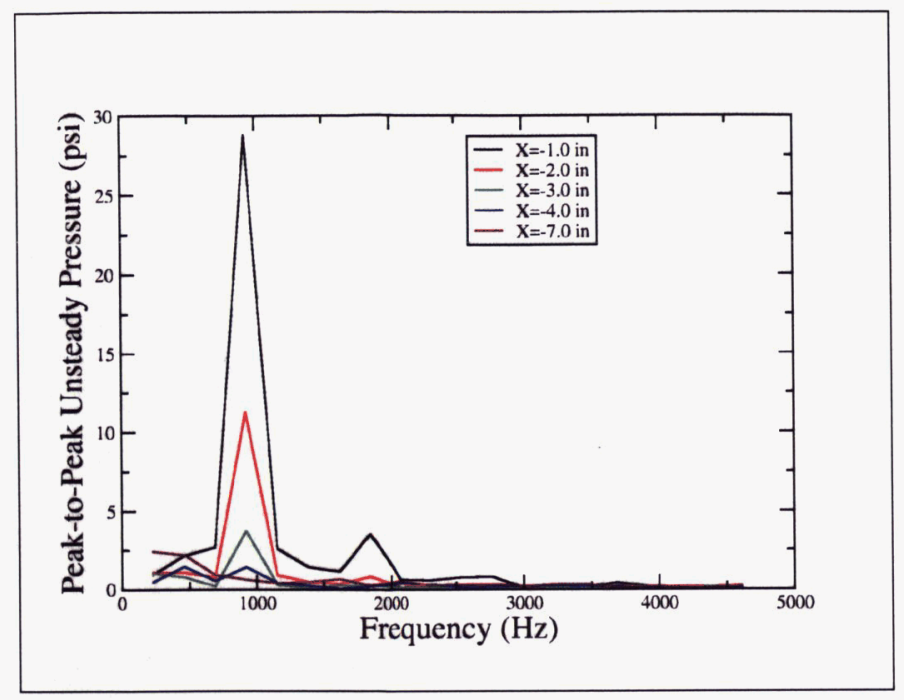

Figure 10. Decomposition of the unsteady pressure upstream of the inducer - LH2.

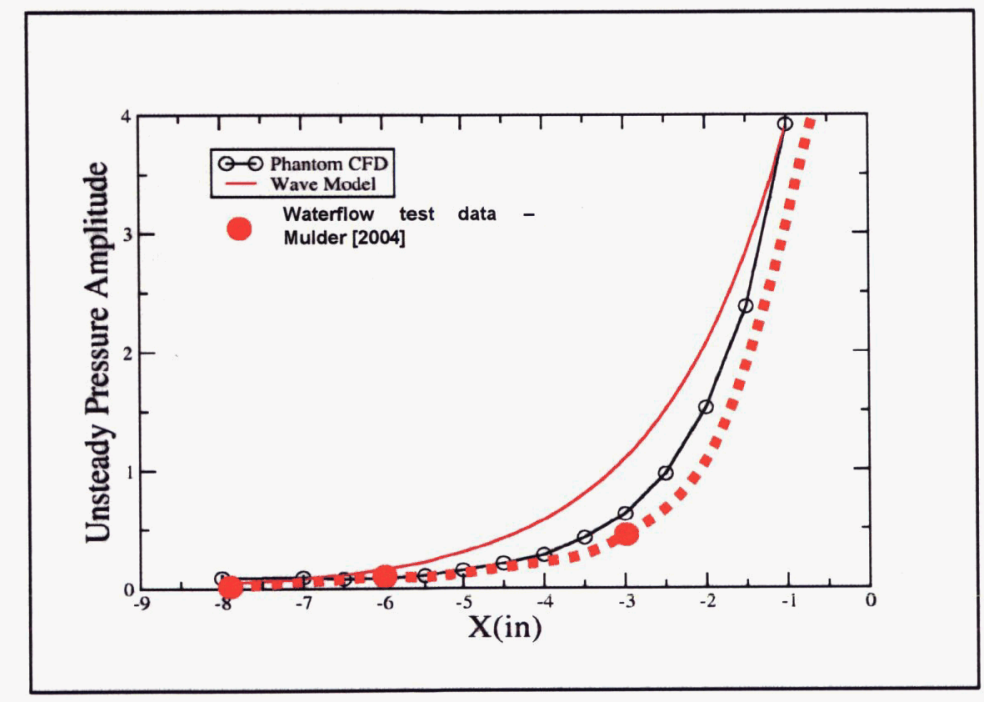

Figure 11. Comparison between unsteady pressure predicted for the full-scale rig with the experimental data from a half-scale rig - $\mathrm{H} 2 \mathrm{O}$. 


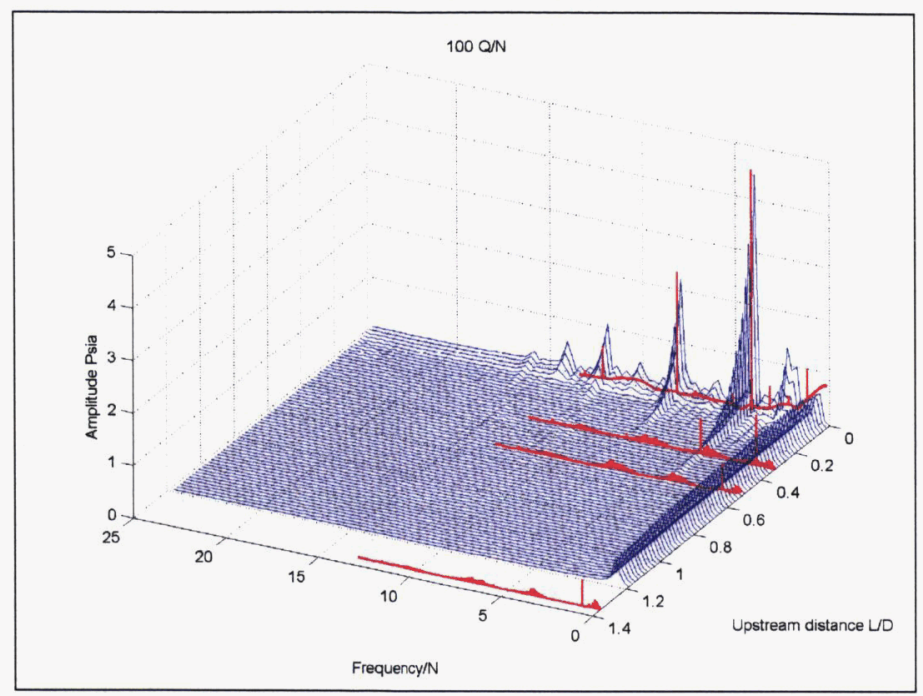

Figure 12. Comparisons between unsteady pressure predicted in half-scale $\mathrm{H} 2 \mathrm{O}$ simulation and half-scale rig data. Test data FFT is marked in red at 4 locations $-100 \% Q / N$.

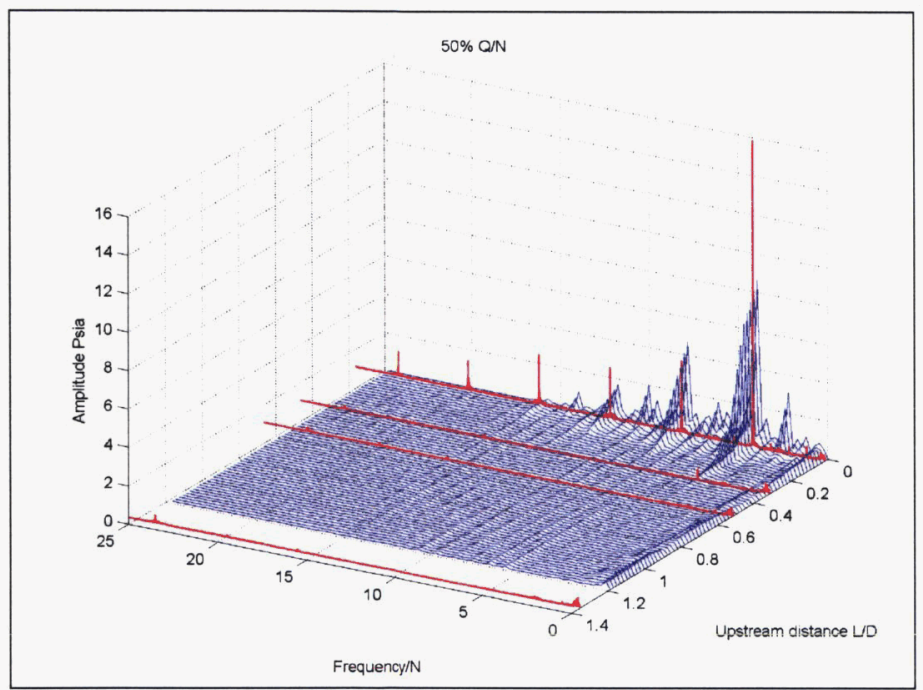

Figure 13. Comparisons between unsteady pressure predicted in half-scale $\mathrm{H} 2 \mathrm{O}$ simulation and half-scale rig data. Test data FFT is marked in red at 4 locations $-50 \% \mathrm{Q} / \mathrm{N}$.

One of the features of the feed line is that it can angulate at the gimbal joint as the engine is rotated in flight. Simulations were performed with the inducer angulated 3 degrees with respect to the feed line. The value of 3 degrees was based on estimates of the maximum deflection during flight. The objective of the simulations was to determine if the angulation generates a spatial $5 \theta$. disturbance which could excite the flow liner structure. Figure 14 and 15 contain contours of the time-averaged static pressure (psi) and velocity ( $\mathrm{ft} / \mathrm{sec}$ ). The angulation in the duct is clearly visible in this figure.

The angulation in the duct causes the resulting pressure and velocity fields to be asymmetric upstream of the inducer. The asymmetric backflow results in the flow liner experiencing different amounts of unsteadiness depending on the circumferential location. Figure 16 shows spatial decompositions of the pressure at the top and bottom sides of the duct near the angulation location. The resultant spatial frequency at $5 \theta$ predicted in the CFD was small, and this fact was later verified in water flow tests [12]. Simulations were also performed at $65 \%$ and $80 \% \mathrm{RPL}$, as well as in $\mathrm{H} 2 \mathrm{O}$. All the simulations showed small levels of unsteadiness at $5 \theta$. 


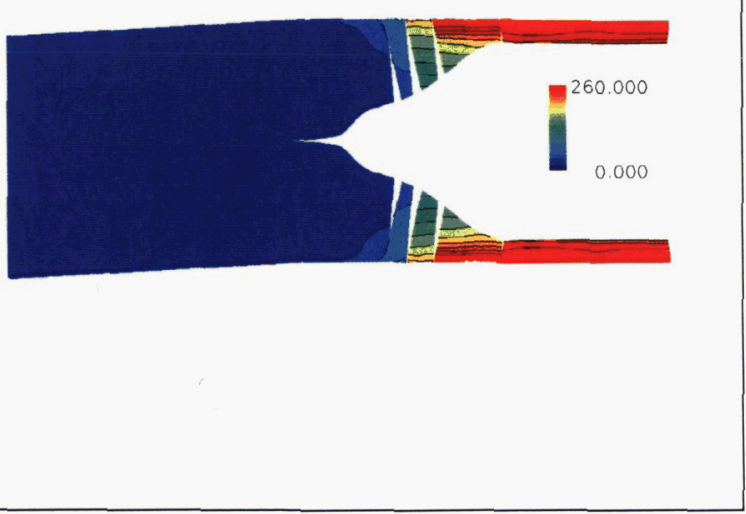

Figure 14. Time-averaged static pressure (psi) for 3-degree angulation simulation - LH2 - 104.5\% RPL.

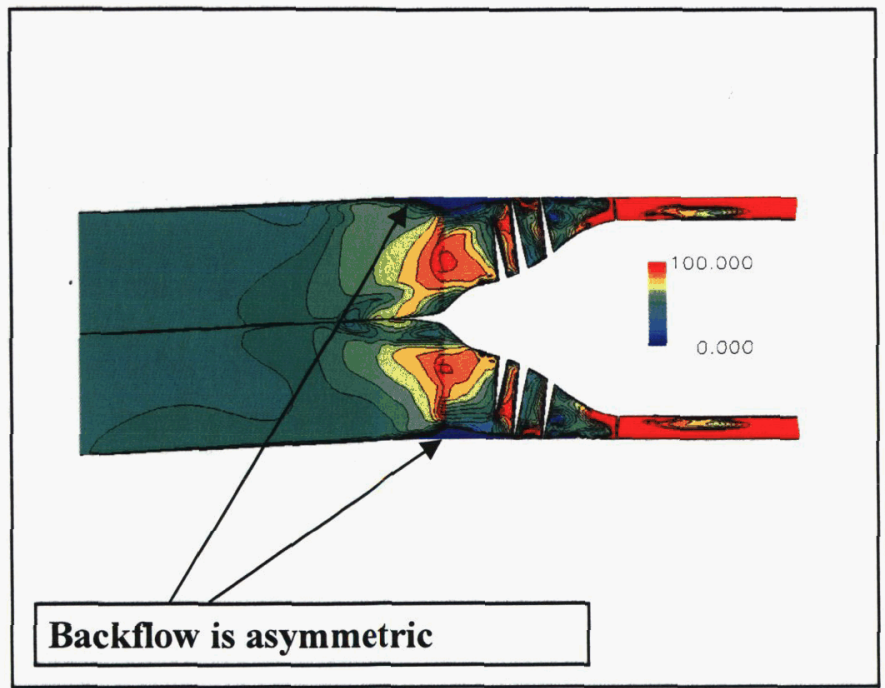

Figure 15. Time-averaged axial velocity (ft/sec) for 3-degree angulation simulation - LH2 - 104.5\% RPL.

Simulations were also performed to study the onset and growth of cavitating flow regions as the inlet pressure was decreased. The simulations were performed for $\mathrm{H} 2 \mathrm{O}$ and were designed to model the experiments of Skelley at al. [11]. The computational grids were refined in the spanwise and streamwise directions for the cavitation simulations, for a total of 4.6 million grid points. In addition, the nominal tip clearance was added to the model. Figures 16 and 17 contain plots of the 0.20 vapor fraction iso-surface for 4 values of the suction specific speed. The onset of the cavitation process is characterized by small regions of cavitation being entrained in the backflow originating from the leading edge tip region of the inducer blades. Increasing the suction specific speed causes the cavitation region to extend further upstream of, and in the inter-blade region downstream of, the inducer leading edge. Further increasing the suction specific speed causes the cavitating flow from the individual blades to coalesce and form a cylinder of cavitation upstream of the leading edge. In addition, the cavitation penetrates further radially into the core flow. Figure 18 shows a comparison of the predicted and experimental values of the total head coefficient as a function of the suction specific speed. The bulk differences in the head coefficient values are caused by the omission of the splitter blades in the simulations. The predictions show the head coefficient fall-off at a lower suction specific speed than indicated by the experimental data. The more rapid fall-off is probably also caused by omitting the splitter blades in the simulations, as well as the need to tune some of the parameters in the cavitation model. Additional simulations are being performed to more accurately determine the breakdown point in the CFD. 


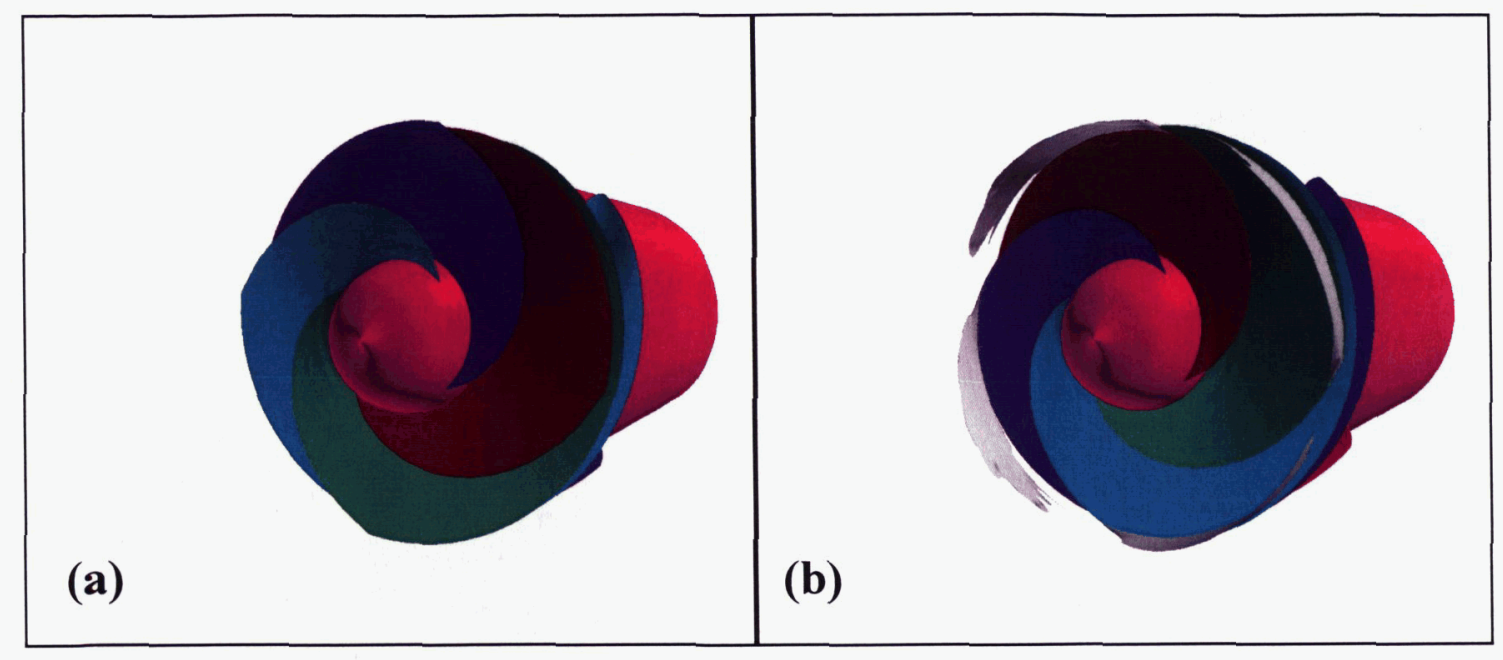

Figure 16. Vapor fraction of 0.20 iso-surface for the LPFP inducer: a) $\mathrm{Pi}=45 \mathrm{psi}, \mathrm{NSS}=5025, \mathrm{~b}) \mathrm{Pi}=\mathbf{1 5 . 2} \mathrm{psi}$, NSS $=11,500$.

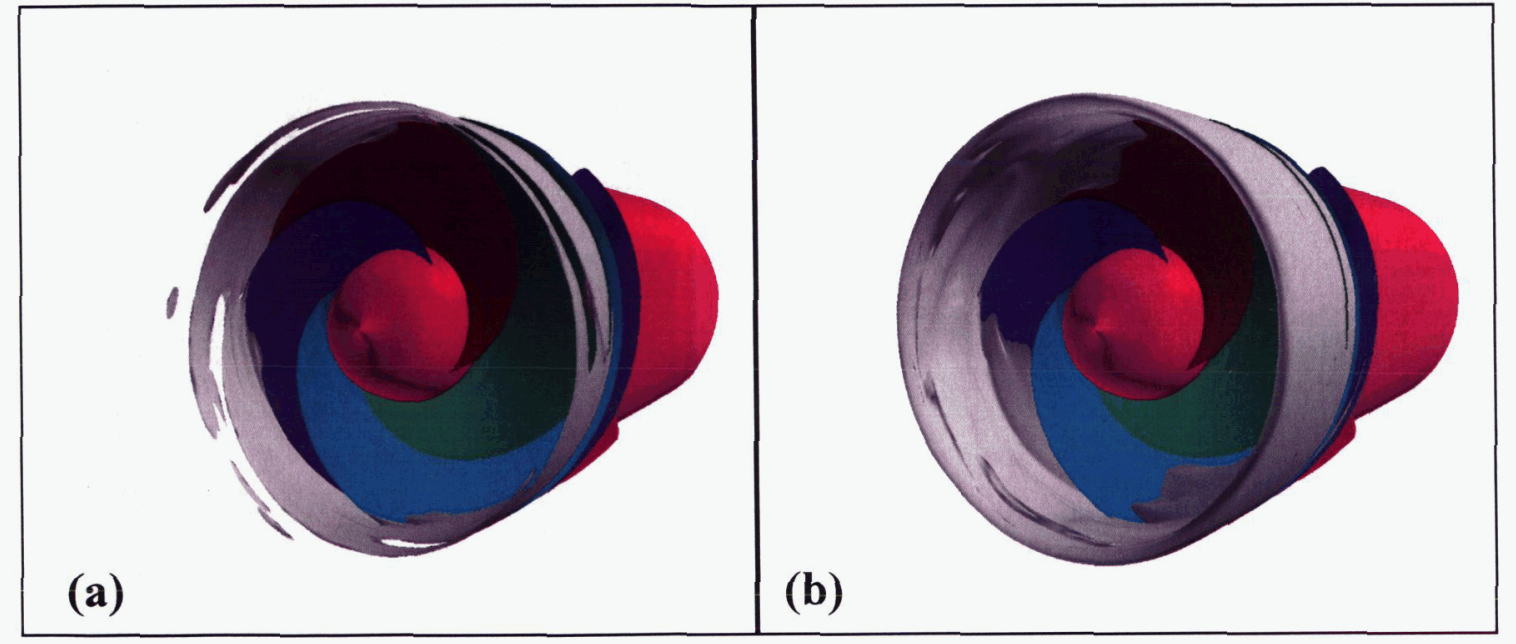

Figure 17. Vapor fraction of 0.20 iso-surface for the LPFP inducer: a) $\mathrm{Pi}=8.7 \mathrm{psi}$, NSS=17,775, b) $\mathrm{Pi}=4.1$ psi, NSS=32,725.

\section{B. ENIGMA Simulations}

Unsteady flow simulations were performed to examine the effect of an elliptical housing and eccentric housing on the pressure perturbations propagated to the downstream flowliner slots. The rationale for looking at these configurations was that it was hypothesized that a non-uniform tip clearance would generate high-order spatial modes that could interact with the flowliner slots. The flow model includes a suction inlet duct and housing and the 4-full blade/4-partial blade inducer with non-uniform tip clearance. Figure 19 shows a schematic of the flow domain. The flow grids were created using the APPT grid tool [15]. The flow model contains about 1.2 million flow nodes and includes the duct and the full-360 inducer.

The flowliner slots were not modeled but enough of the suction inlet duct was modeled to envelop the location of the slots. Figure 20 shows the overlapping grid system used and the location of key geometrical elements. 


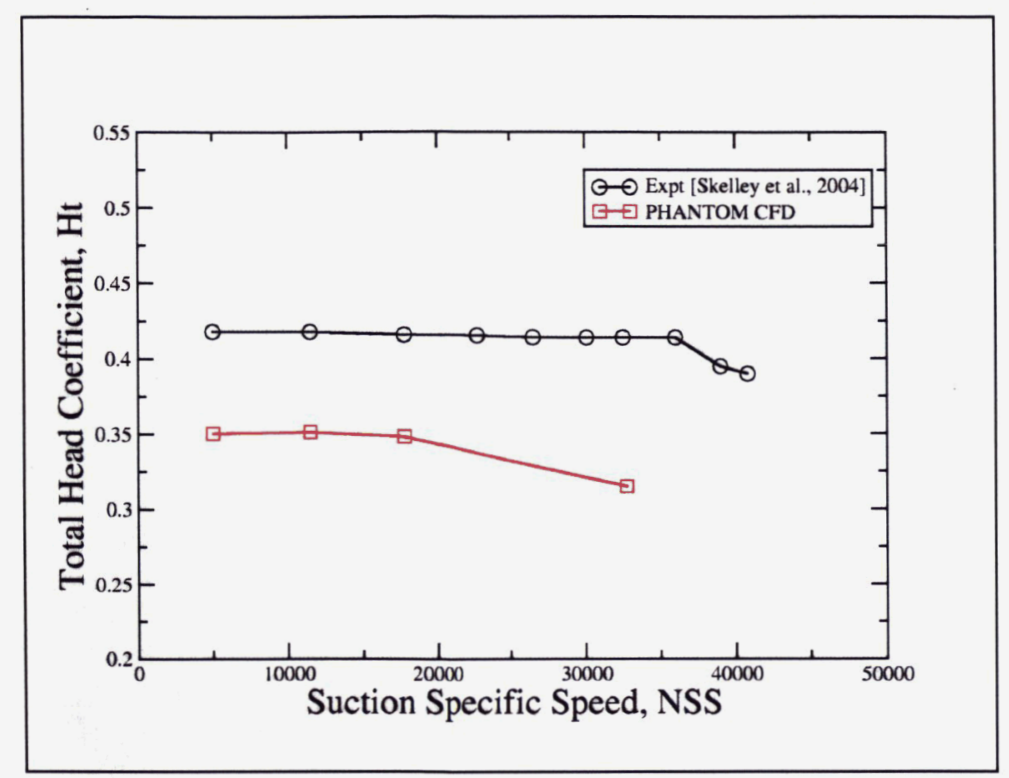

Figure 18. Predicted and experimental values of total head coefficient as a function of suction specific speed.

The elliptical tip clearance model has a spatial period of 180 degrees with a $\mathrm{min} / \mathrm{max}$ tip clearance distribution of $0.004 \% / 0.01 \%$. The elliptical tip clearance represents a centered rotor within a housing that is not circular. The eccentric tip clearance model has a spatial period of 360 degrees and a $\min / \mathrm{max}$ tip clearance distribution of $0.004 \% / 0.01 \%$. The eccentric clearance model represents the situation when the rotor is not centered with the housing.

Unsteady results were calculated for 104.5\% RPL conditions with LH2. The calculations utilized a sliding mesh with the inducer blade hub and blade mesh rotating relative to the fixed duct and housing. The numerical time-step was selected so that the numerical Nyquist frequency was about $23641 \mathrm{~Hz}$. Computed pressure time signals and fast-Fourier transforms (FFTs) are shown in Figs. 21 and 22. Figures 21 and 22 also show the generation of the blade passage frequency $(\mathrm{N})$ harmonics, $4 \mathrm{~N}, 8 \mathrm{~N}, 12 \mathrm{~N}$ etc. The character of the harmonics is similar for both the elliptical and eccentric tip clearance cases.

The interaction of inducer blade perturbations with the non-uniform tip clearance is illustrated in Figs. 23 and 24. The spectrum shows the spatial $(\theta)$ modal content, at an instant of time, of the circumferential pressure distribution near the downstream slots. The pressure distribution contains about 100 points. The character of the harmonics is different for both the elliptical and eccentric tip clearance cases. Because of the symmetry of the elliptical tip clearance distribution, a $2 \theta$. mode is generated due to the tip clearance-blade interaction (Fig. 23). For the eccentric tip clearance simulation, a $1 \theta$ mode and a very weak $5 \theta$ are generated due to the tip clearance-blade interaction (Fig. 24).

\section{Conclusions}

A series of numerical simulations have been performed for the feed line and low pressure fuel pump inducer of the Space Shuttle Main Engine in an effort to determine possible fluid dynamic mechanisms generating cracks in a flow liner upstream of the inducer. The results of a series of the numerical simulations in liquid hydrogen and water showed close agreement with results of hot-fire and water flow tests. The simulations and experiments indicate that unsteadiness generated by the low-pressure fuel pump inducer probably plays a major role in the generation of the cracks, as the dominant frequency of the unsteadiness is in the vicinity of several structural frequencies. Angulation of the duct upstream of the inducer and asymmetric tip clearance do not appear to contribute directly to the crack generation process. 




Figure 19. Perspective view of flow model for elliptical and eccentric tip clearance study.

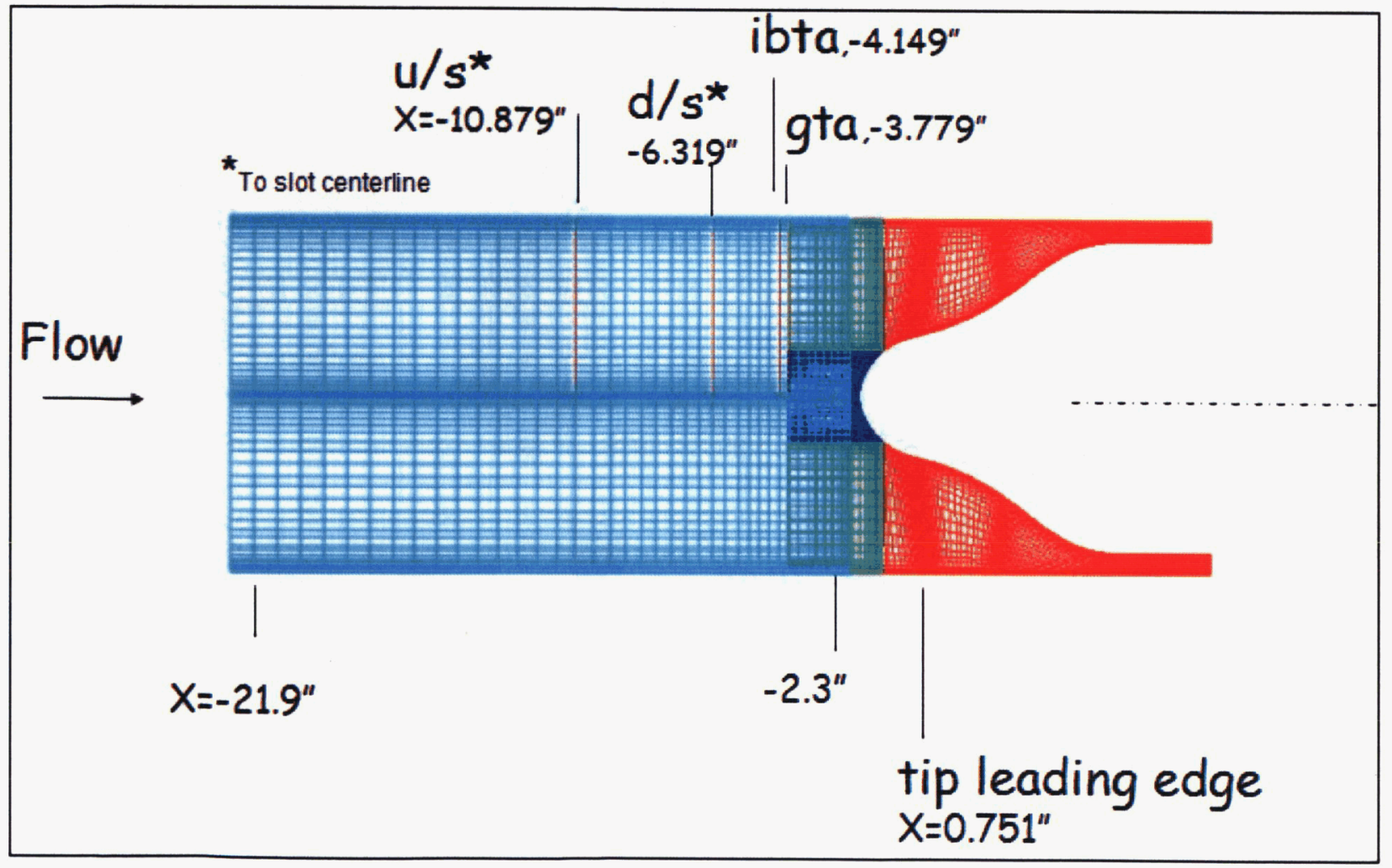

Figure 20. Duct and inducer meridional grid plane: $d / s$ indicates the location of the downstream slots relative to the flow model. 


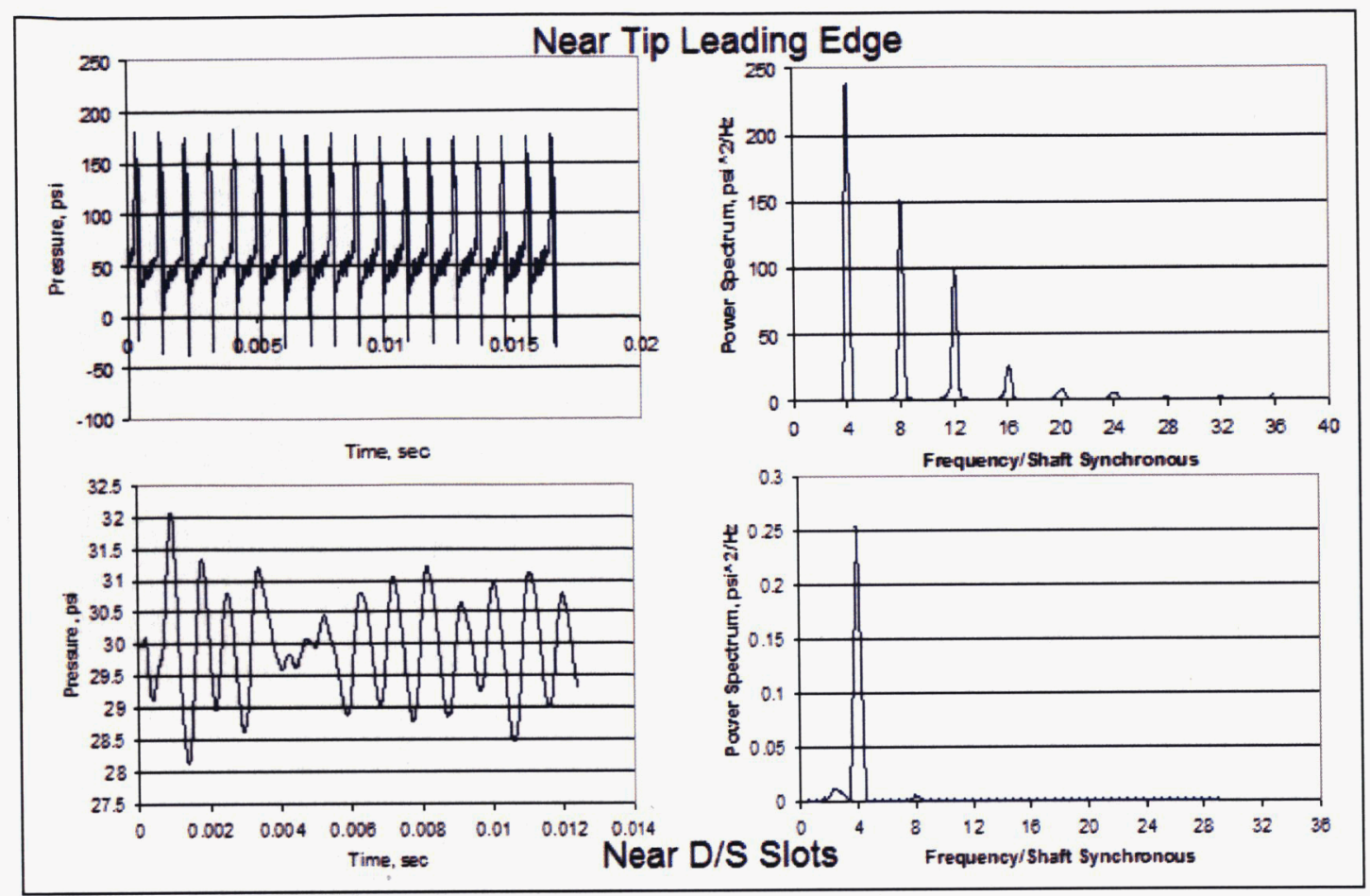

Figure 21. Elliptical tip-clearance distribution: computed pressure time signals and spectrums near tip leading edge and near flow liner downstream (D/S) slot location.

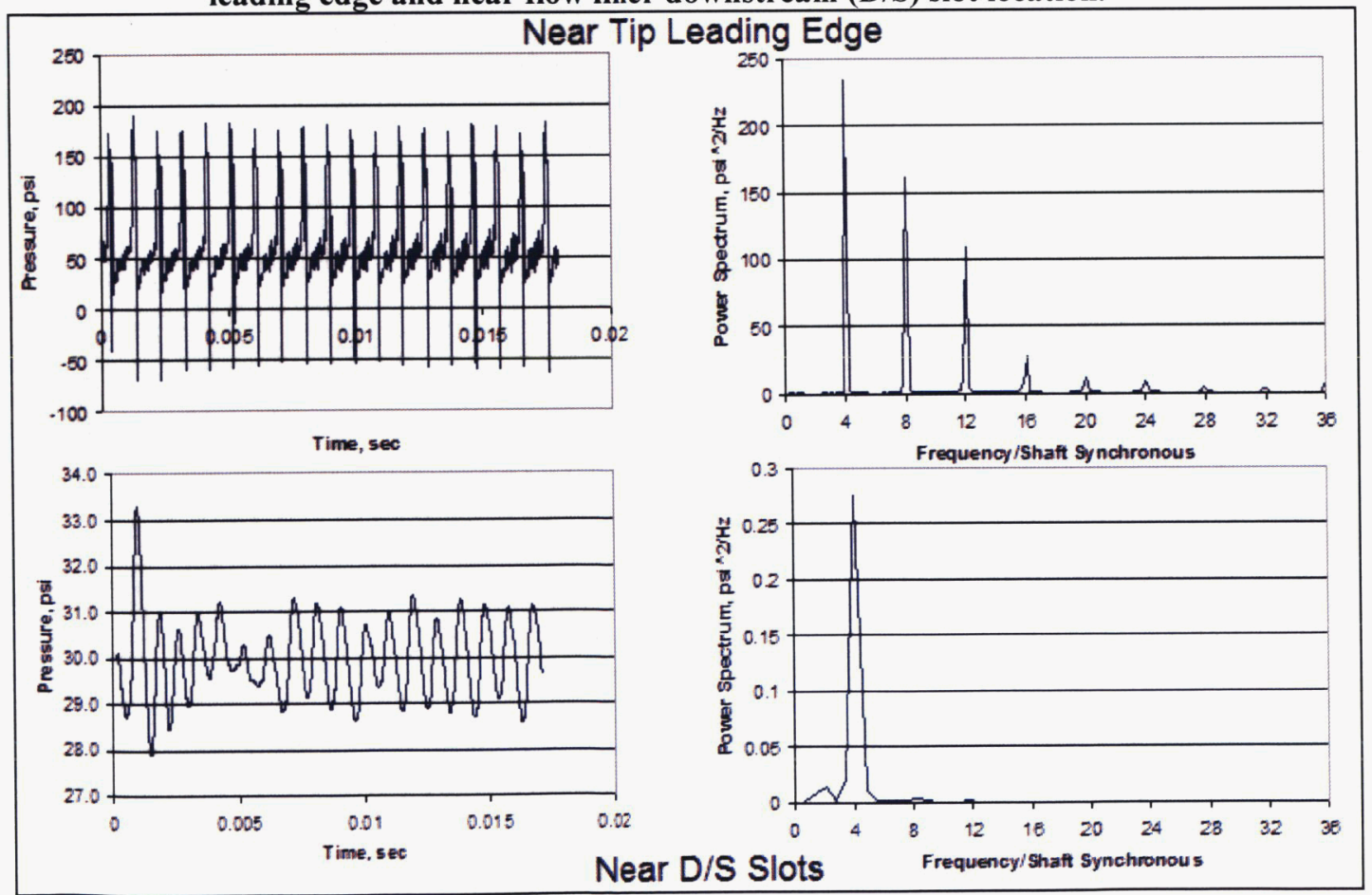

Figure 22. Eccentric tip-clearance distribution: computed pressure time signals and spectrums near tip leading edge and near flow liner downstream (D/S) slot location. 


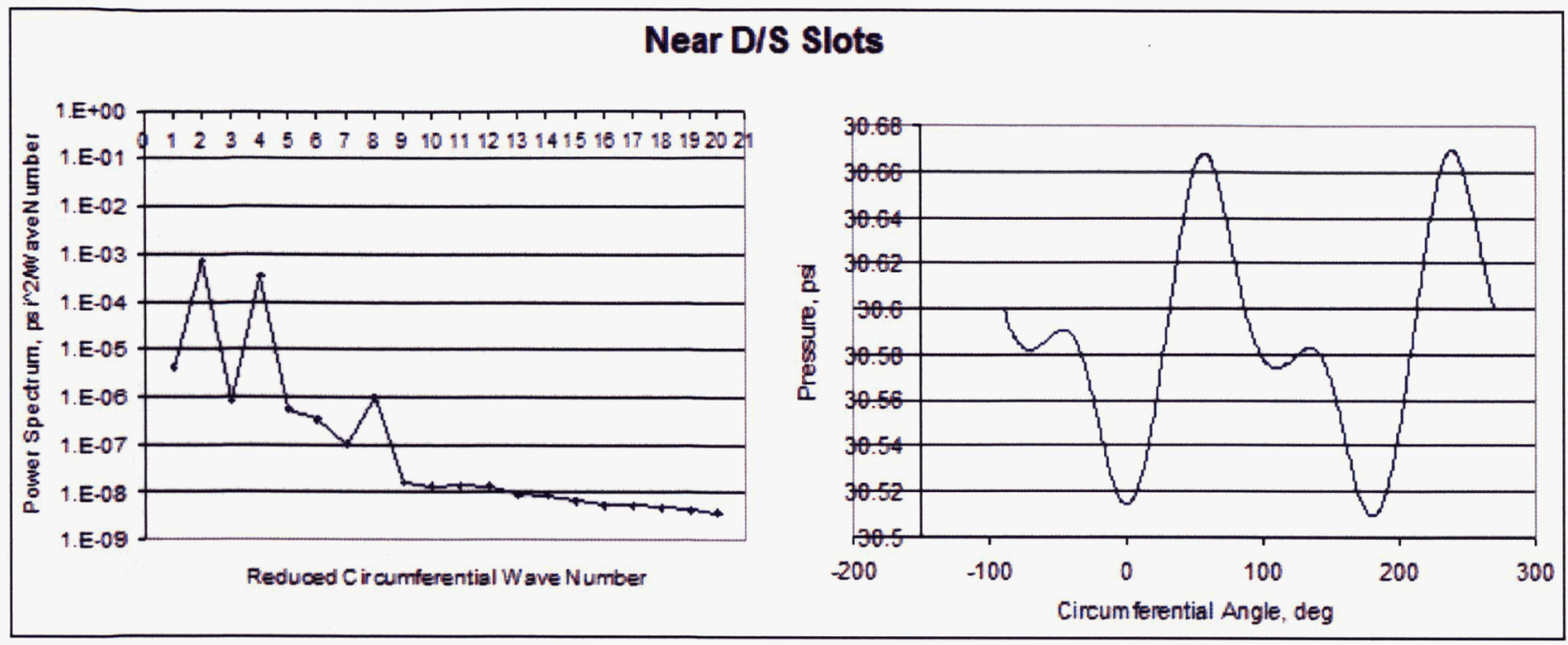

Figure 23. Generation of $2 \theta$ with elliptical tip clearance model.

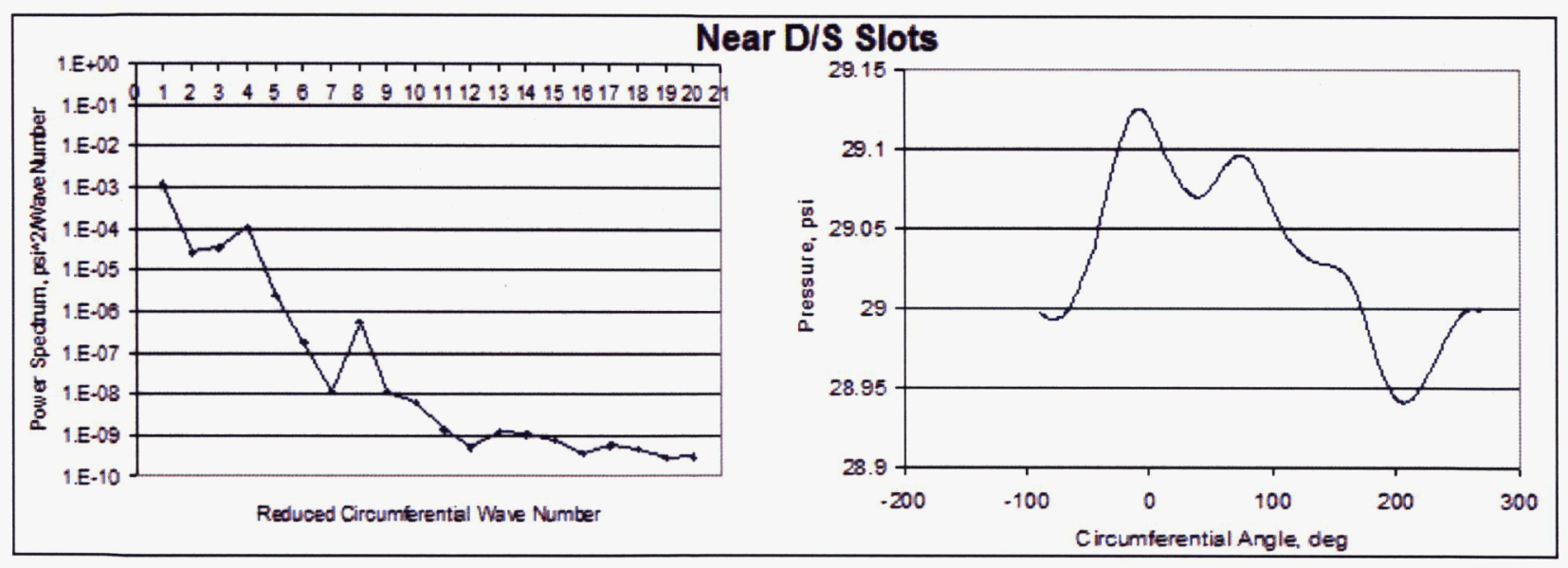

Figure 24. Generation of weak $5 \theta$ with eccentric tip clearance model.

\section{Acknowledgments}

Several of the simulations were performed on the SGI Altix clusters at NASA Ames Research Center, and the authors would like to thank Mr. Chuck Niggley for facilitating the use of the systems.

\section{References}

${ }^{1}$ Sondak, D. L. and Dorney, D. J., "General Equation Set Solver for Compressible and Incompressible Turbomachinery Flows," AIAA 2003-4420, 39th AIAA/ASME/SAE/ASEE Joint Propulsion Conference and Exhibit, Huntsville, AL, July 20-23, 2003.

${ }^{2}$ Williams, M., "A Helmholtz Pressure Equation Method for the Calculation of Unsteady Incompressible Viscous Flows," Int. J. Numer. Meth. Fluids, Vol. 14, 1992, pp. 1-12.

${ }^{3}$ Baldwin, B. S., and Lomax, H., "Thin Layer Approximation and Algebraic Model for Separated Turbulent Flow," AIAA Paper 78-257, Huntsville, AL, January, 1978.

${ }^{4}$ Oefelein, J. C., Sandia Corporation, Livermore, CA, Private Communication, December, 2002.

${ }^{5}$ http://webbook.nist.gov/chemistry/fluid 
${ }^{6}$ Merkle, C. L., Feng, J.-Z., and Buelow, P. E. O., "Computational Modeling of the Dynamics of Sheet Cavitation, “ Third International Symposium on Cavitation, Grenoble, France. April, 1998.

${ }^{7}$ Ahuja, V., Hosangadi, A., and Ungewitter, R. J., "Simulations of Cavitating Flows in Turbopumps," AIAA 2003-1261, $41^{\text {st }}$ AIAA Aerospace Sciences Meeting \& Exhibit, Reno, NV, January 6-10, 2003.

${ }^{8}$ Dorney, D. J., and Sondak, D. L., "Application of the PHANTOM Analysis to Impeller and Diffuser Geometries," 52nd JANNAF Propulsion Meeting, Las Vegas, NV, May 10-13, 2004.

${ }^{9}$ Williams, M., Chen, W., Brozowski, L., and Eastland, A., "Three-Dimensional Finite Difference Method for Rotordynamic Fluid Forces on Seals", AIAA Journal, Vol. 35, No.8, 1997, pp. 1417-1420.

${ }^{10}$ Williams, M., Dianaty, A, McGlynn, R., and Clever, W., "Numerical Prediction of Inducer Cavitation", AIAA Paper 20042641, 34 ${ }^{\text {th }}$ AIAA Fluid Dynamics Conference, Portland, OR, June 2004.

${ }^{11}$ Skelley, S., "SSME Low-Pressure Fuel Pump Water Test (P2397) - Configuration 1: SSME LPFTP w/RS84 Shroud", Preliminary Data Review \#2, NASA Marshall Space Flight Center, August, 19, 2004.

${ }^{12}$ Abd-El-Malek, M. B., and Sarwat, N. H., "Sound Attenuation in a Circular Duct of a Viscous Medium in the Absence of Mean Flow, Nonlinear Mathematical Physics, Vol. 4, No. 1-2, 1997, pp. 231-240.

${ }^{13}$ Zoladz, T., Private Communication, June, 2004.

${ }^{14}$ Mulder, A., "SSME Low Pressure Fuel Pump Inducer Water Flow Test (P2397) - Series 1d (RS84 Shroud Configuration," Preliminary Unsteady Data Review, NASA Marshall Space Flight Center, August 19, 2004

${ }^{15}$ Clever, W., Private Communication, March, 2004. 
Unsteady Flow Interactions Between the LH2 Feed Line and SSME LPFP Inducer

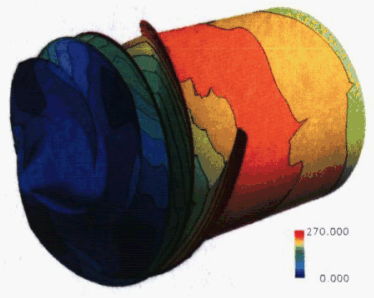

Dan Dorney and Lisa Griffin NASA Marshall Space Flight Center MSFC, AL

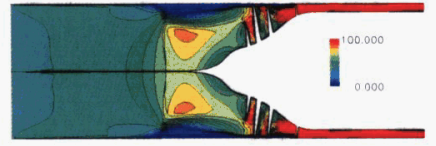

Bogdan Marcu and Morgan Williams Pratt \& Whitney - Rocketdyne Canoga Park, CA

42 ${ }^{\text {nd }}$ AIAA/ASME/SAE/ASEE Joint Propulsion Conference

- Background and motivation

- Numerical methods

- Numerical simulations

- single and two-phase flow

- comparisons with data

- Conclusions 


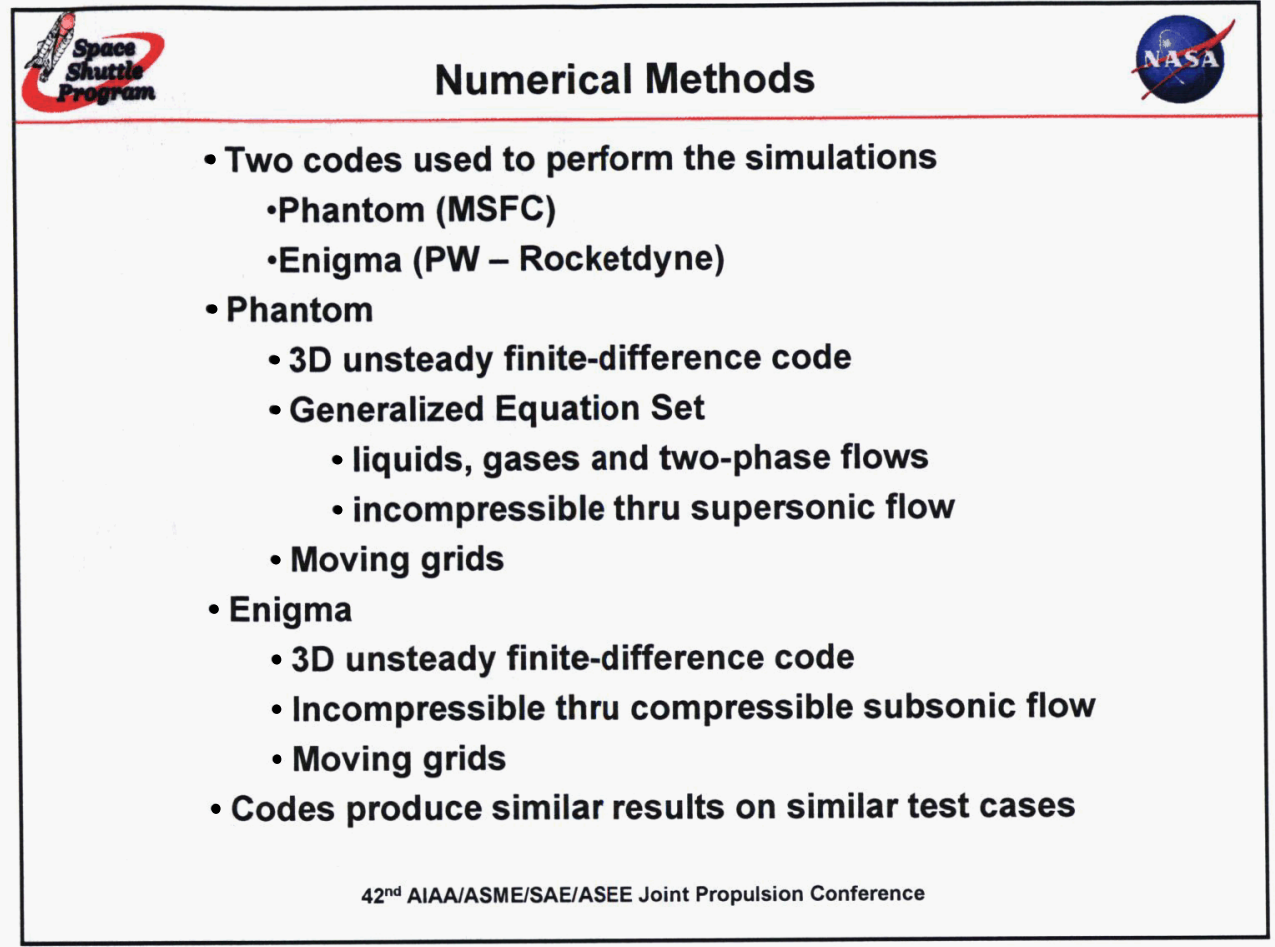

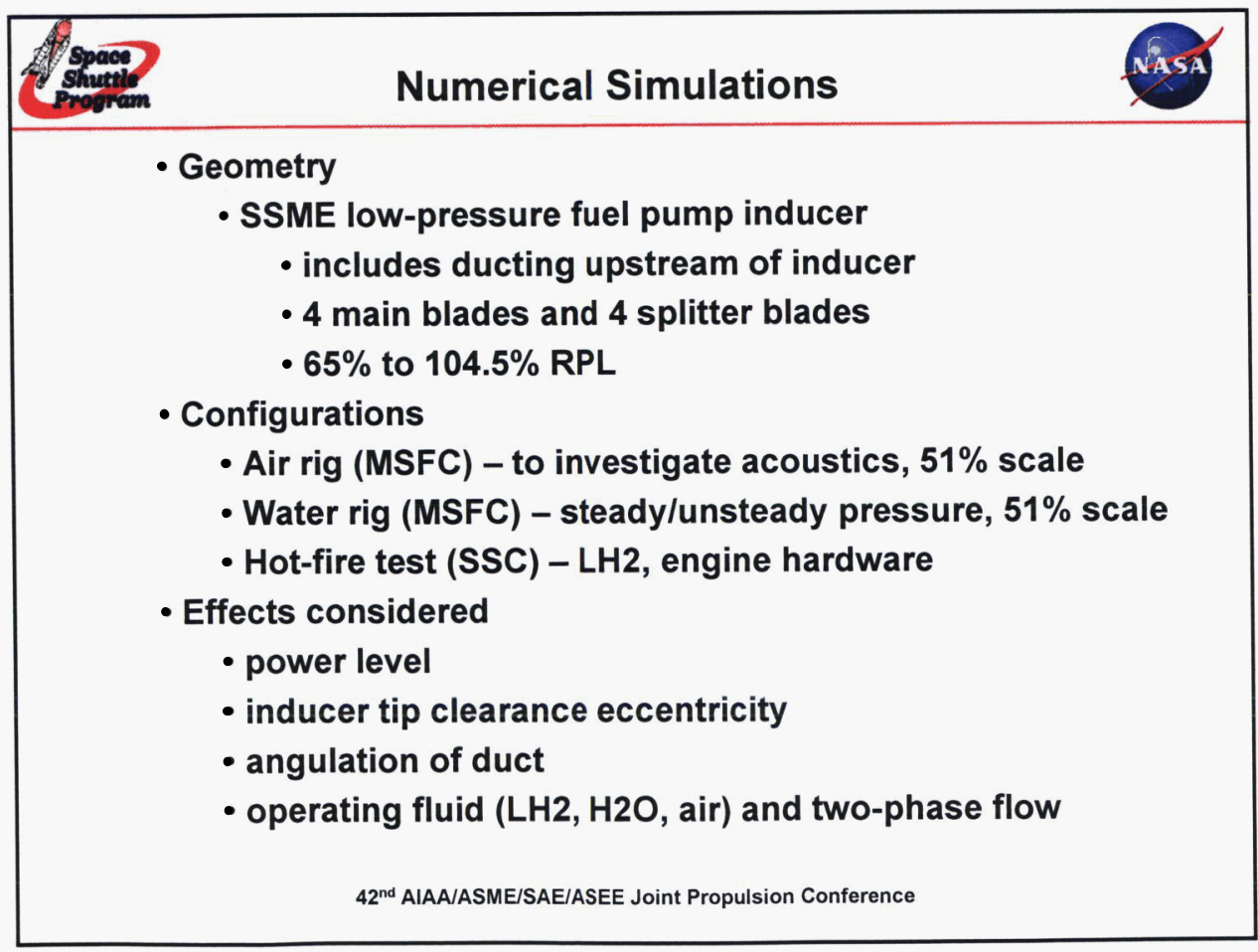


- Full 360 degree simulation

- splitter blades neglected

- 22 inches of upstream duct modeled

- full-scale (hot-fire) and $51 \%$ scale (H20, air) models

- 2.8 million and 4.6 million grid points

- LH2, H2O and air

- single and two-phase flow

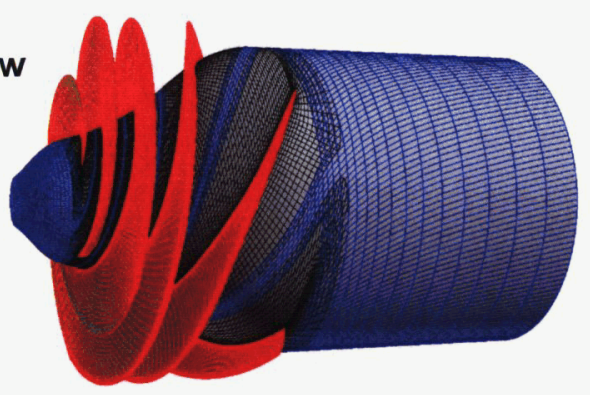

Time-averaged static pressure (psi) for LH2 at 104.5 RPL
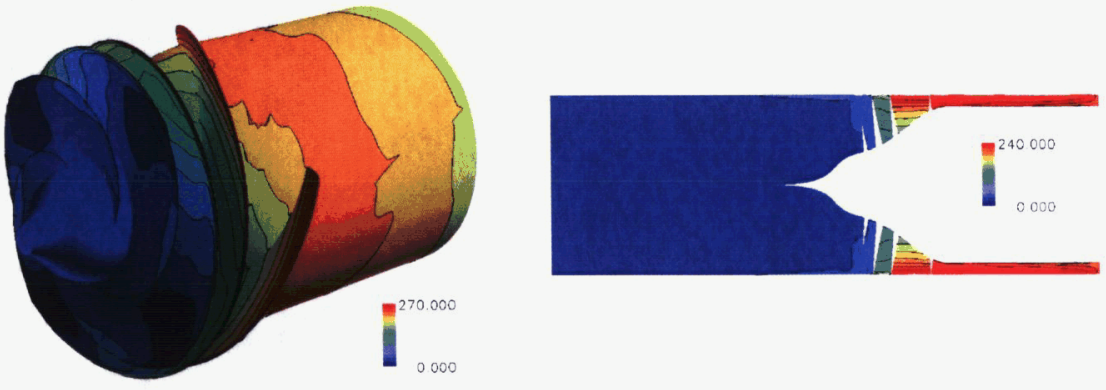

- Large loading near the tip leading edge $\rightarrow$ leads to backflow

- Low pressures noted on suction side of the tip leading edge $\rightarrow$ location where inception of cavitation usually occurs 


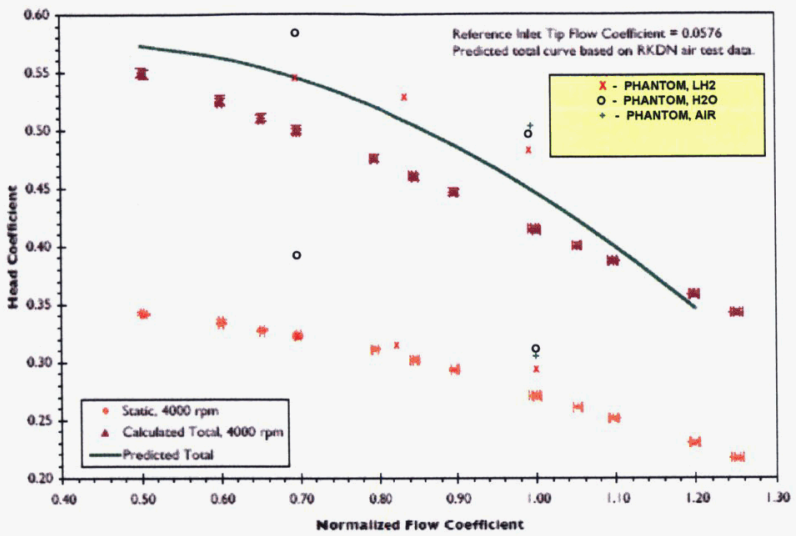

Comparison of predicted head coefficients in air, $\mathrm{H} 2 \mathrm{O}$ and $\mathrm{LH} 2$ (all full-scale) with data obtained in the $51 \%$ scale water-rig tests

42 $^{\text {nd }}$ AIAA/ASME/SAE/ASEE Joint Propulsion Conference

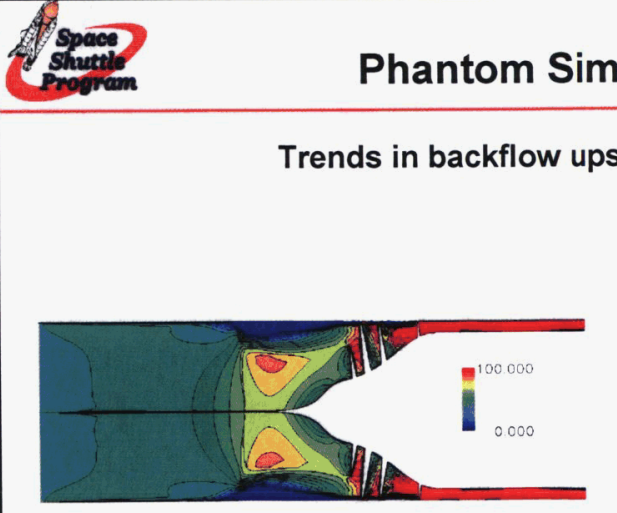

Axial velocity (ft/sec) for $104.5 \% \mathrm{RPL}-\mathrm{LH} 2$

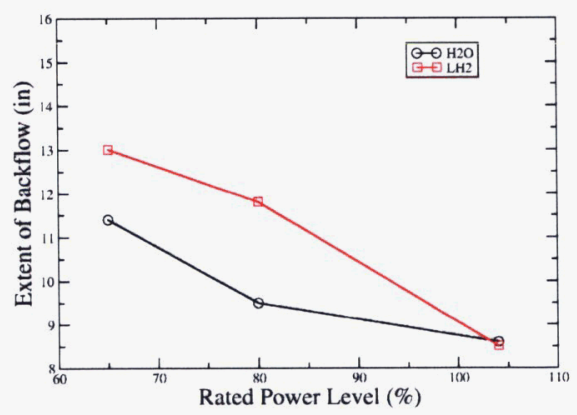

Backflow from inducer reaches the downstream slot for all flow conditions, and envelopes the entire flow liner between $65 \%$ and $80 \%$ RPL (note: more cracks were observed in the downstream slots) 
Decay of the unsteady pressure waves upstream of the inducer - LH2
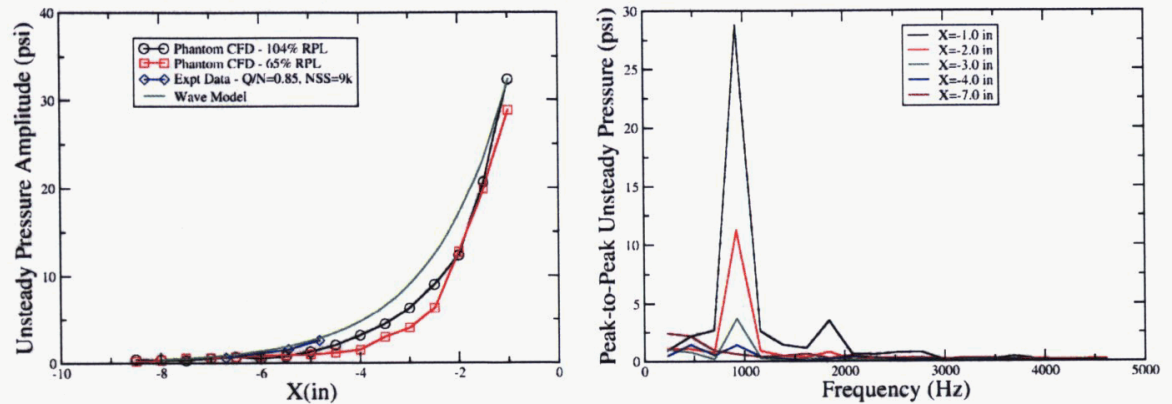

- The predicted decay matches well with the results of an analytical wave model and hot-fire data

- The unsteadiness is reduced, but not insignificant, when is reaches the flow liner

- The predominant unsteadiness is at the inducer blade passing frequency (or a harmonic)

42 $^{\text {nd }}$ AIAA/ASME/SAE/ASEE Joint Propulsion Conference

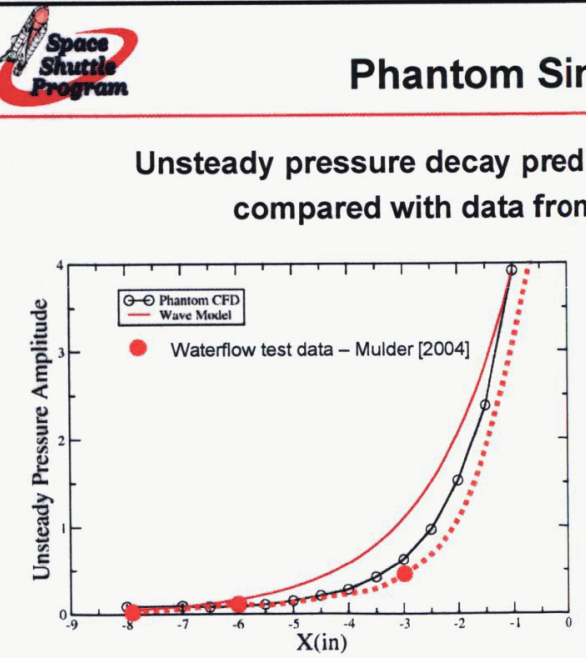

\section{Phantom Simulations - VI}

Unsteady pressure decay predicted in full-scale $\mathrm{H} 2 \mathrm{O}$ simulation compared with data from $51 \%$ scale water rig tests

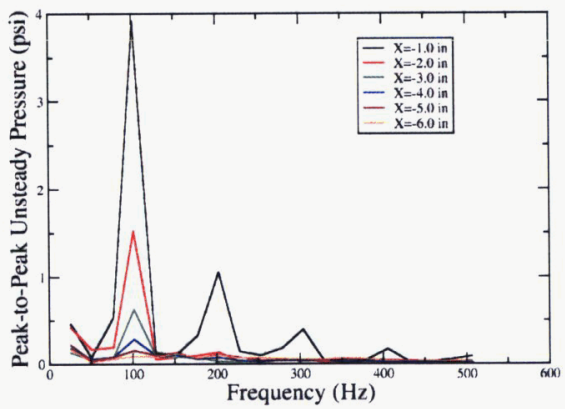

- Very good agreement between predicted results and test data

- Predominant frequency at inducer blade passing frequency or harmonics 


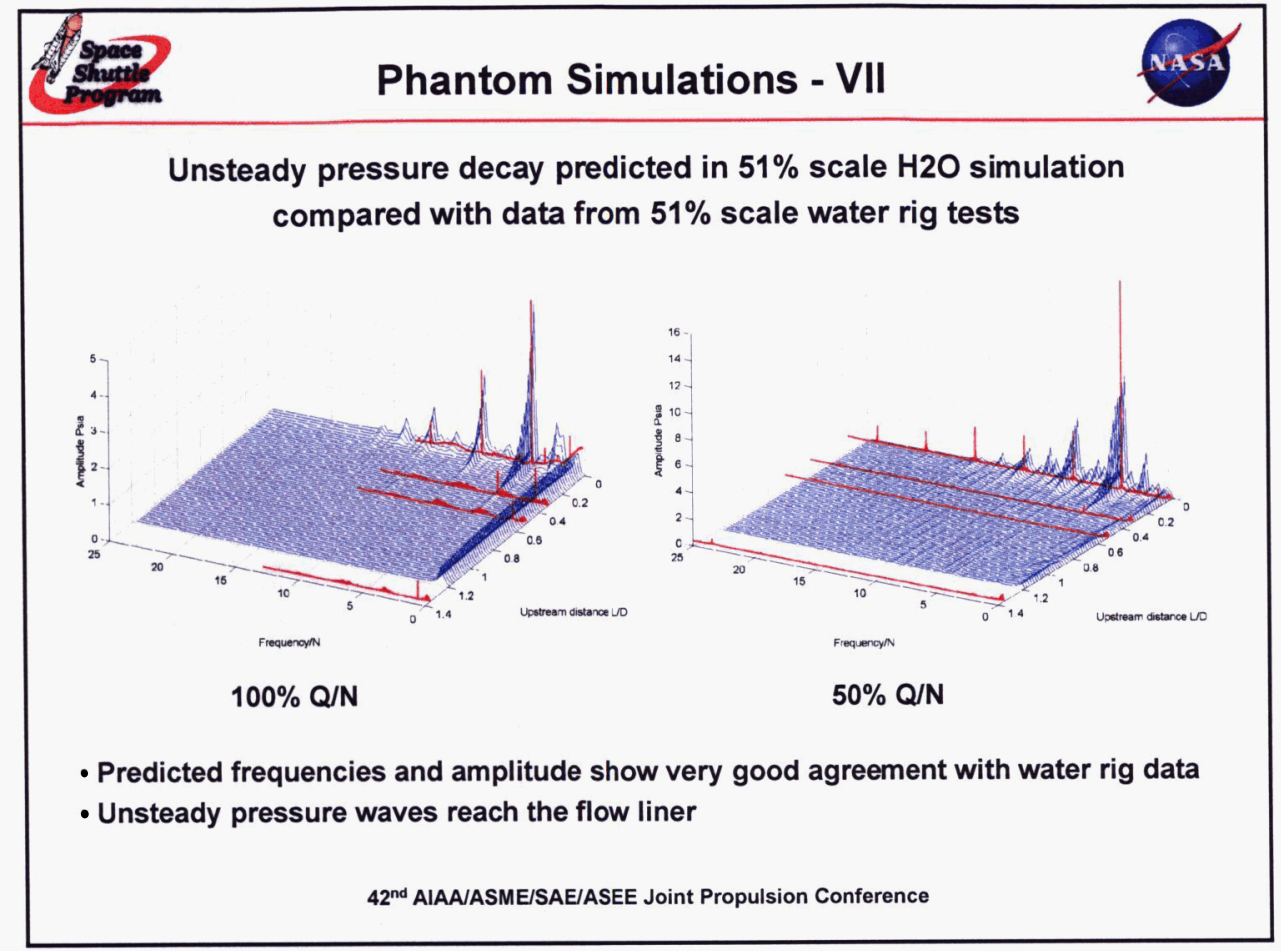

Effects of 3 deg duct angulation (engine movement)
Time-averaged static pressure (psi)
- 3 degree angulation corresponds to maximum value expected during flight
- Duct angulates at approximately the midpoint of the flow liner
- Toncern is the generation of unsteadiness at 50
- The backflow is asymmetric on the top and bottom sides of the duct
and bottom sides of the duct
$42^{\text {nd }}$ AlAA/ASmE/SAE/ASEE Joint Propulsion Conference



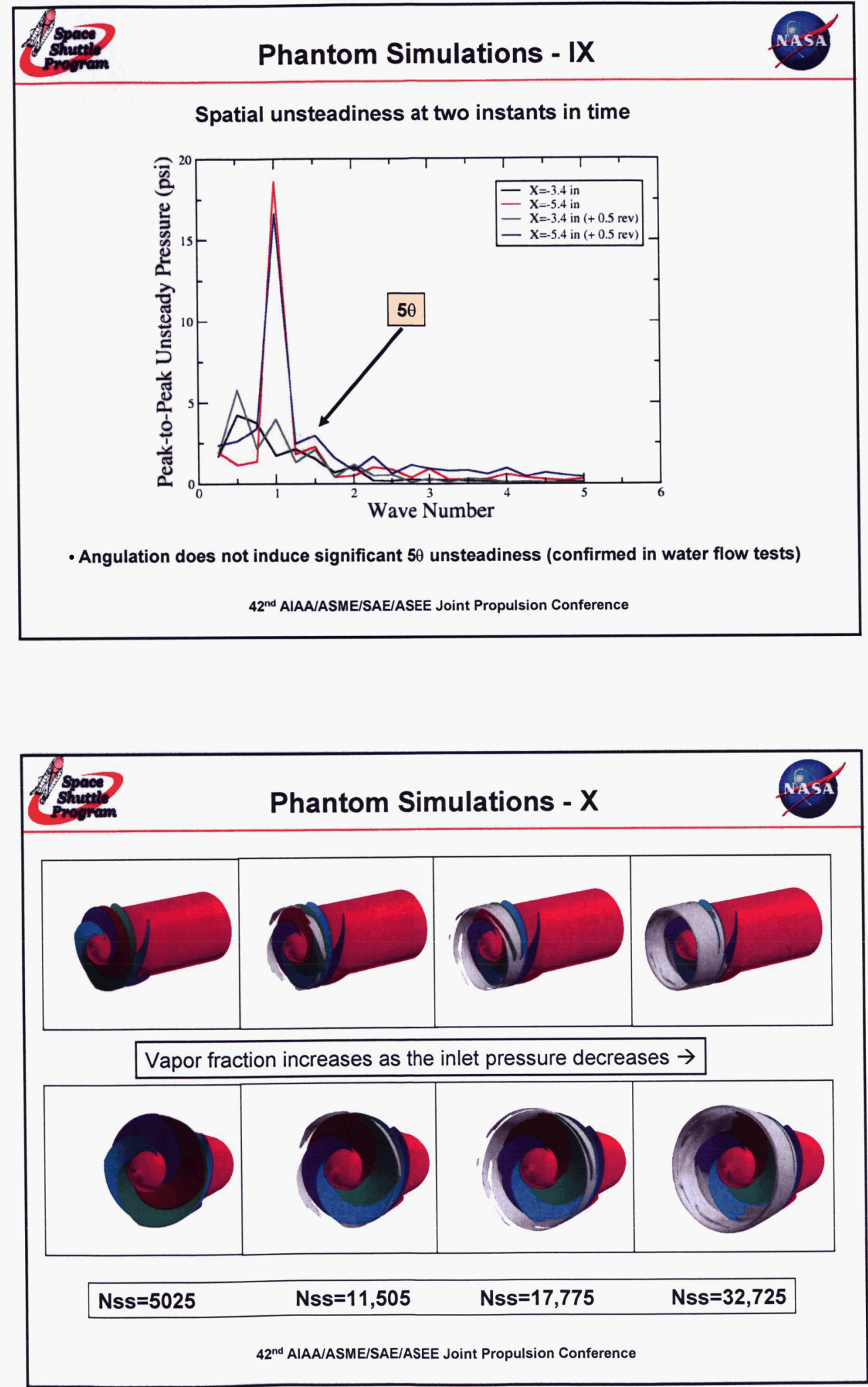


- Full 360 degree simulation

- splitter blades included

- 25 inches of upstream duct modeled

- full-scale model, eccentricity effects included

-1.2 million grid points

- LH2

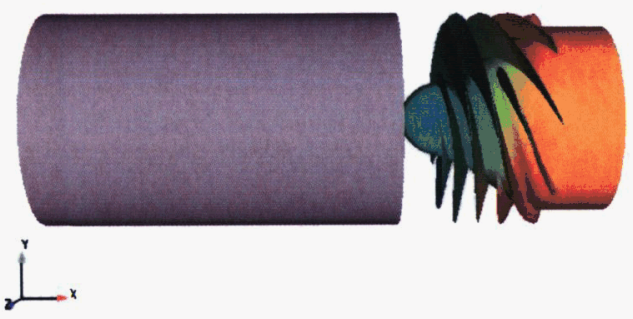

\section{Enigma Simulations - II}

Elliptical tip-clearance distribution
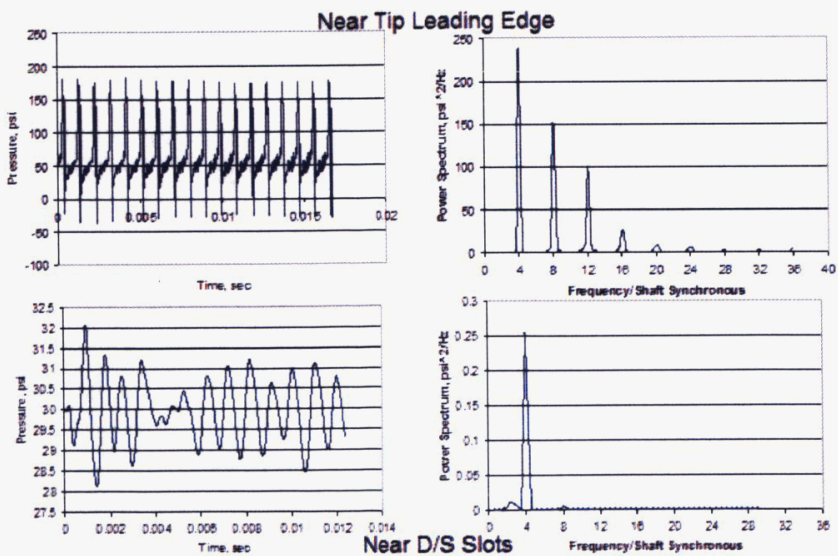

Predicted pressure time signals/spectrums at 2 locations

42 ${ }^{\text {nd }}$ AIAA/ASME/SAE/ASEE Joint Propulsion Conference 

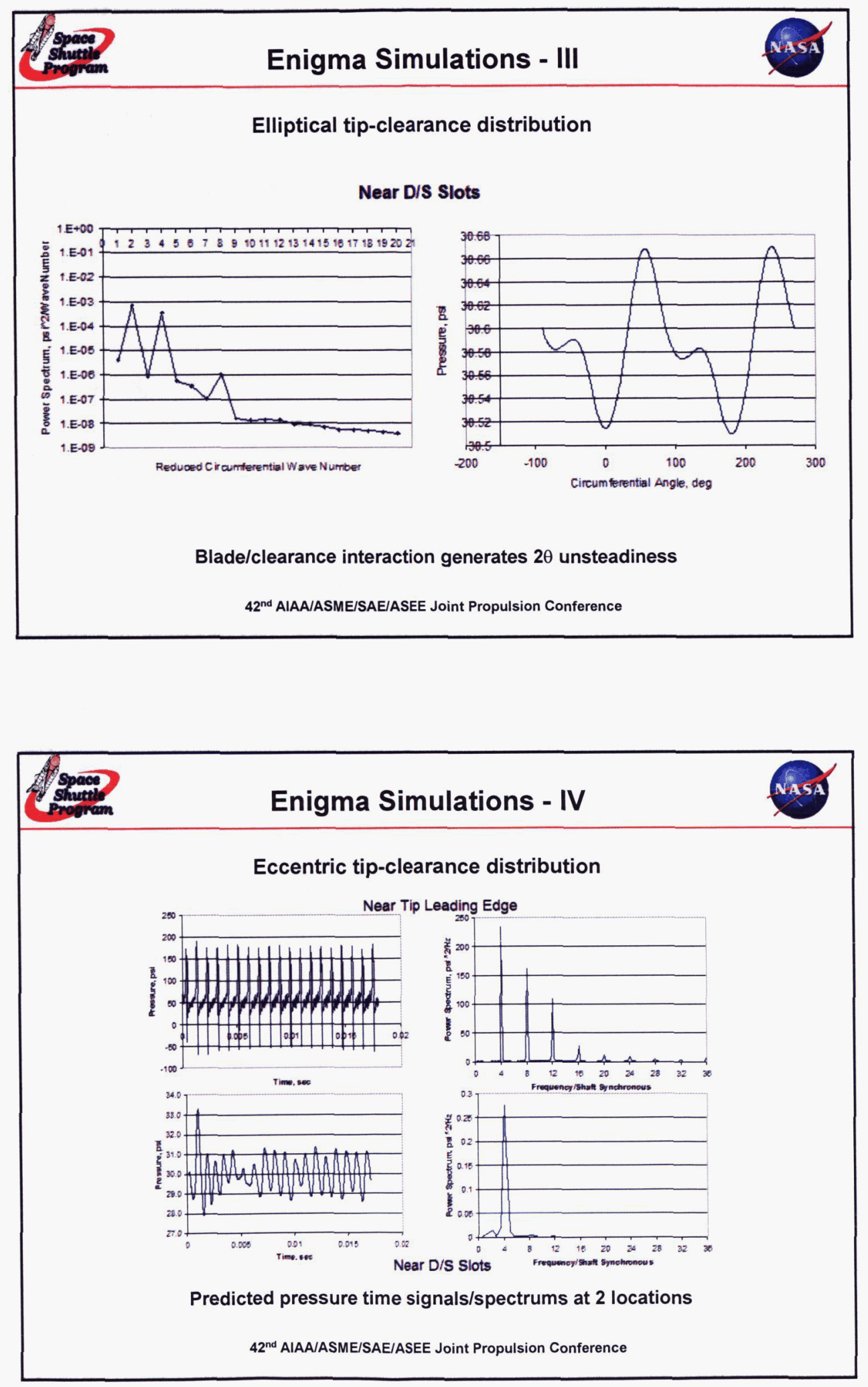


\section{Enigma Simulations - V}

Eccentric tip-clearance distribution



Near D/S Slots

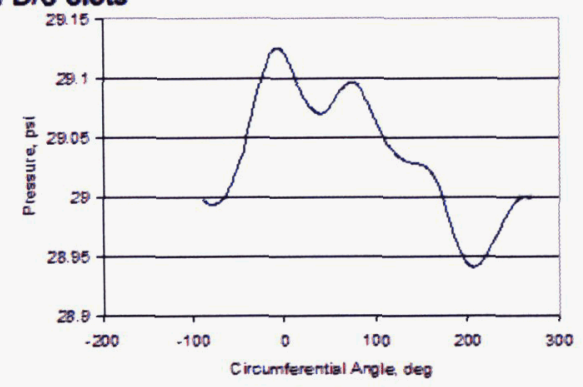

Blade/clearance interaction generates $1 \theta$ and weak $5 \theta$ unsteadiness

$4^{\text {nd }}$ AIAA/ASME/SAE/ASEE Joint Propulsion Conference

- Extensive analytical, computational and experimental program to determine the interaction of the SSME low-pressure fuel pump inducer with a flow liner located upstream

- Two codes, Phantom and Enigma, were used to study the effects of operating fluid, power level, asymmetric clearance, duct angulation and two-phase flow on the unsteadiness produced from the inducer

- The predicted results, in general, show good agreement with the results of water-rig and hot-fire tests

- The predicted and experimental data show significant unsteadiness near several structural frequencies

- Duct angulation and asymmetric clearance probably not big contributors in the crack generation process 